\title{
Views on the Past, Present, and Future of Business and Information Systems Engineering
}

\author{
Wil M. P. van der Aalst • Jörg Becker • Martin Bichler · Hans Ulrich Buhl · \\ Jens Dibbern · Ulrich Frank · Ulrich Hasenkamp • Armin Heinzl • \\ Oliver Hinz $\cdot$ Kai-Lung Hui • Matthias Jarke - Dimitris Karagiannis • \\ Natalia Kliewer · Wolfgang König • Jan Mendling • Peter Mertens • \\ Matti Rossi - Stefan Voss · Christof Weinhardt $\cdot$ Robert Winter $\cdot$ Jelena Zdravkovic
}

Published online: 12 November 2018

(C) Springer Fachmedien Wiesbaden GmbH, part of Springer Nature 2018

\section{The Times They Are a-Changin}

"The times they are a-changin," a famous song title by Bob Dylan, also applies to our profession and our subject of study. Information technology has always been a driver for innovation. The recent years, however, have seen IT-based innovations that truly impact everybody's lives. Everything that can be digitized will be digitized, and this trend is continuing at an amazing speed. For a discipline that looks at the design and utilization of information systems these are exciting times. Yet, it is also a time full of challenges. While our discipline has

Prof. Dr. W. M. P. van der Aalst · Prof. Dr. M. Jarke

RWTH Aachen University, Aachen, Germany

Prof. Dr. J. Becker

University of Münster, Münster, Germany

Prof. Dr. M. Bichler $(\square)$

Department of Informatics, Decision Sciences and Systems,

Technical University of Munich (TUM), Boltzmannstr 3,

85748 Munich, Germany

e-mail: bichler@in.tum.de

Prof. Dr. H. U. Buhl

University of Augsburg, Augsburg, Germany

Prof. Dr. J. Dibbern

University of Bern, Bern, Switzerland

Prof. Dr. U. Frank

University of Duisburg-Essen, Duisburg, Germany

Prof. Dr. U. Hasenkamp

University of Marburg, Marburg, Germany

Prof. Dr. A. Heinzl

University of Mannheim, Mannheim, Germany much to contribute, it competes with other disciplines for topics and ideas. Also, the scope of topics studied has become broader and broader, and so have our methods. While initial work in Business and Information Systems Engineering (BISE) was often rooted in artificial intelligence, database systems, or operations research, the community has adopted new approaches to address new types of problems. Nowadays, we also have a strong group of academics working primarily with empirical methods or methods from microeconomics, to name just a few. This development towards a more multiparadigmatic discipline also had its challenges and there were controversial discussions along the way.

Prof. Dr. O. Hinz · Prof. Dr. W. König

Goethe University Frankfurt, Frankfurt, Germany

Prof. Dr. K.-L. Hui

Hong Kong University of Science and Technology,

Clear Water Bay, Hong Kong

Prof. Dr. D. Karagiannis

University of Vienna, Vienna, Austria

Prof. Dr. N. Kliewer

Freie Universität Berlin, Berlin, Germany

Prof. Dr. J. Mendling

Vienna University of Economics and Business, Vienna, Austria

Prof. Dr. P. Mertens

University of Erlangen-Nürnberg, Erlangen, Germany

Prof. Dr. M. Rossi

AIS President, Atlanta, USA

Prof. Dr. M. Rossi

Aalto University, Helsinki, Finland 


\subsection{The Situation in 2012}

When I took on the post as Editor-in-Chief (EiC) of the journal in 2012, this was shortly after some intense debates about design-orientation versus empirical methods in our field. There was still a danger that the discipline would split into subgroups. I personally always viewed this as very undesirable and still think that the community will have a bright future if it manages to leverage the synergies by combining different approaches. Most of nowadays problems cannot be solved with one approach only and some questions require design science, while others lend themselves to a formal treatment or a thorough empirical analysis. Ultimately this depends on the research question asked. Combining the expertise in different methods bears the potential to understand and solve problems from a more holistic point of view.

We have aimed to further position BISE as a top European journal that certainly has strong design-oriented departments, but that is open to different methods and problems as long as they are related to the overall mission, namely to publish "research on the effective and efficient design and utilization of information systems by individuals, groups, enterprises, and society for the improvement of social welfare." I was fortunate to have two Vice-EiCs, Armin Heinzl and Robert Winter, who shared this vision.

A first and important task was the revision of the $d e$ partment structure. Hans Ulrich Buhl had already introduced four departments, but now, after the discussions in the community, we thought the time ripe for a revision. The departments should reflect the major subgroups and research streams of our discipline. In addition, we aimed to include the top people in the field for each of these subgroups. These departments should also provide a response to the frequent question "What is this discipline all about?" While BISE is a rather generic acronym, the departments give an up to date view of important and tangible research streams in our field ranging from "Business Process Management" to "Management and Use of Information and Knowledge." These departments are not set in stone, but they should provide a more long-term view on important research streams in the field.

Prof. Dr. S. Voss

University of Hamburg, Hamburg, Germany

C. Weinhardt

Karlsruhe Institute of Technology, Karlsruhe, Germany

Prof. Dr. R. Winter

University of St. Gallen, St. Gallen, Switzerland

Prof. Dr. J. Zdravkovic

Stockholm University, Stockholm, Sweden
BISE is also our community journal and as such we aimed to have the best scholars in the field on board and set further incentives to actively contribute. For this, we passed new bylaws that determine a tenure period for all levels of a three-tier hierarchy, Associate Editors, Department Editors, and also the EiC and the Vice-EiCs. This should make sure that there is always change, that colleagues naturally rotate off the board in regular terms and allow for young scholars to join. For colleagues who contribute to the journal there thus is a path to move up the ladder and take on more and more responsible jobs in our journal over time.

The new department structure allowed us to better manage the heterogeneity of the community and to set a number of department-specific activities. First, we actively involved senior scholars but also high potentials in the different departments to join as Associate and Department Editors. Ultimately, it is the editorial board that signals the quality of the journal. Then we started various marketing activities targeting conferences and workshops relevant to the specific departments. The fact that BISE had its own department of Business Process Management (BPM), for example, made it an attractive outlet for researchers who presented their work at the BPM conference. We also fostered the ties with other conferences such as Wirtschaftsinformatik, ECIS, and ICIS, where we regularly get the best papers overall or from a conference stream that relates to one of our departments.

The three-tiered governance structure also allowed us to reach the submission numbers that we have today without losing quality or sacrificing response times. While the number of associate editors has grown, we still have an average cycle time in the first round of about 2 months only. At the same time, the workload for most reviewers and associate editors remained reasonably low. The new bylaws with fixed tenure times set additional incentives for reviewers and associate editors to do a good job as this will be taken into account for eventual promotion.

\subsection{Development of the Journal}

Academic journals have become more important in the last years. Particularly in the economic and social sciences, publications in journals are seen as an important means to measure the quality of research. They illustrate how a field develops and which contributions the discipline makes to important questions of our time. If the community journal is developing well, this is taken as a sign for the community. The trend towards journal publications became more pronounced at least 10 years ago and, indeed, this journal developed very well in the past 10 years, in particular after the decision was made to publish in English (see "The BISE Journal in Numbers" in this issue for developments 
since 2007, when Hans Ulrich Buhl became Editor-inChief). The number of submissions rose from 71 in 2007 to 271 in 2017 , and the number of downloads from around 12,000 to 190,179 in the same time period. The SCI Impact Factor, the 5-year Impact Factor, and the SNIP has also increased and made remarkable jumps in the past few years. They are now at the same level or even above those of A+-ranked Anglo-American Information Systems journals. These citation metrics also stand out compared to German and most European journals in business and economics. This is particularly remarkable, because the number of literature reviews is very low in our journal compared to original research contributions, and review articles are known to yield much higher citation rates.

Actually, our goal was never to "engineer" the citation metrics, but to have high-quality and original research contributions - the meat of every community. Citation metrics are heavily criticized nowadays as they reveal little about the quality of a journal or its standing in a community. The San Francisco Declaration on Research Assessment, ${ }^{1}$ publications by the German Research Foundation, ${ }^{2}$ and the Wissenschaftsrat ${ }^{3}$ make this a prominent point. A niche journal with one highly cited paper can already have an impressive impact factor. This says very little about the quality of the work published in this journal in general.

What is more important than these numbers is the observation that BISE is nowadays regarded not only as the flagship journal of the German-speaking community, but as one of the, if not the top European journal in the field. This is impressive considering that the journal was published in German only 10 years ago mainly targeting the Germanspeaking market. We now have a diverse set of authors and editorial board members from Europe and from all over the world. While there is a natural and historical focus on the central European countries, we have gradually repositioned the journal to become a European journal. Just recently, the BISE journal has been included into the Erasmus Journal List, which is widely used for tenure decisions in Europe and beyond, not to speak about top quality ratings in other national journal rankings.

Most importantly, we have managed to position the journal as central outlet for all subgroups of the BISE community. This acceptance among all sub-communities might have been our biggest challenge when we started out. Today, I am glad to see young scholars eager to become reviewers or Associate Editors in our journal and that it is accepted among those who are more on the

\footnotetext{
$\overline{1}$ https://sfdora.org/.

2 http://www.dfg.de/download/pdf/dfg_im_profil/reden_stellungnah men/download/empfehlung_wiss_praxis_1310.pdf.

3 http://www.wissenschaftsrat.de/download/archiv/4609-15.pdf.
}

empirical side as well as those who build systems or develop theory.

\subsection{We've Come a Long Way}

The fortunate development of the journal has many roots. I was fortunate to follow a very active set of editors in the past two decades such as Ulrich Hasenkamp, Peter Mertens, Wolfgang König, and Hans Ulrich Buhl. An important decision was that of Hans Ulrich Buhl to publish the journal in English 10 years ago, a time when I still acted as Department Editor. The effort for this change must not be underestimated. There was significant pushback from some in our community. Acceptance could be gained via the triple strategy, which allowed us to publish in both languages for several years. This was only possible due to the support of companies such as Deutsche Bank, McKinsey, and SAP, to name just a few. The latter two have continued their support until now, helping us in various promotional activities.

Nowadays, BISE is only published in English and targeted at the research community, while Wirtschaftsinformatik und Management is published in German targeting practitioners in the field. I am still convinced that the decision to publish the research journal in English was the right decision as it allows researchers who do not speak German to read and understand our work. The development of journals, which continued to publish in German language only, seems to provide further evidence. Some are struggling or have even ceased to exist.

I believe that in more recent years a number of decisions outlined earlier helped us to further grow. First of all, I am happy to see authors from related fields in business and informatics who did not submit to our journal in the past. I am also very proud of the talents that we have on our editorial board as Associate and Department editors. Including top talents will remain one of our most important signs of quality and one of the most important activities of my successors. The three-tier governance has allowed us to scale the operations to the 271 submissions that we have right now, but also to provide high-quality review reports in due time. The new bylaws set additional incentives to be active and get promoted for those who contribute to the journal and the community.

Many new activities are on the way. We are working on a data and replication policy, an effort that I consider hugely important for the long-term well-being of a quality journal. Given the various research traditions, it is also not easy to find a policy that ensures reliable research results, but does not at the same time create high barriers for certain types of research. We are constantly working on new special issues and set initiatives that, hopefully, serve the well-being of our community in a way that our journal 
continues to be a vibrant platform for the exchange of new ideas and initiatives in our field.

\subsection{Thank You}

My time as Editor-in-Chief was a work-intensive but also a very rewarding period. I am leaving the position with an incredible mixture of feelings. I am excited to think about the new possibilities that await me with more time in my schedule, but I am also sad to leave a position that has been so satisfying. Over the years I have come to know many of the authors and reviewers whom I first met by reading their manuscripts and letters. Later I met these authors and reviewers at conferences and saw their careers flourish. Many have become close colleagues.

I received a lot of support from many people in the community, more than I expected. I am particularly grateful to my dear colleagues Armin Heinzl, Wil van der Aalst, and Robert Winter, who served as Vice EiCs in the past couple of years. I would really like to thank Hans Ulrich Buhl for his constant support and all his efforts to strengthen the journal and the community throughout the years. Ulrich Hasenkamp has been leading the editorial office all along guaranteeing the high quality of our journal in the final stages after acceptance of the manuscript. I am also very grateful to my team in Munich. Marianne Thanner and Paul Karaenke both did an outstanding job in keeping track and monitoring the hundreds of review processes in parallel. Last but not least, I'd like to thank our industry partners McKinsey and SAP for their continued support, as well as Peter Pagel and the team at Springer.

Prof. Dr. Martin Bichler

Technical University of Munich

\section{Perceptions of the Past, Present, and Future of BISE}

\subsection{Inception (The Very Past)}

I am not sure whether a 60 -year anniversary is the right moment to draw an intermediate conclusion regarding the virtues and challenges of a scholarly journal but it is definitely a good opportunity. Thus, I will be sharing some thoughts from the perspective of an academic who has been offering a considerable part of his trajectory for contributing to BISE's journey from a top national towards a renowned international outlet.

To start this journey, we have to go back to the late 1980s. A scholarly journal which exploited the title of a young interdisciplinary field as its label seemed to be special. Written in capital letters, WIRTSCHAFTSINFORMATIK claimed to be the German-speaking academic outlet at the intersection of business administration and computer science. Headed by Peter Mertens, a highly admired colleague who contributed strong foundations for our discipline, the signaling made evident for authors where to publish if the information should reach practice and if the advancement of academic careers was aimed at. Thus, I got in contact with the predecessor of BISE by submitting and reviewing a significant number of articles during my early academic stages at the WHU and the University of Bayreuth as well as heading the interview section for almost a decade.

In 1998, Wolfgang Koenig, my academic teacher, succeeded Peter Mertens as Editor-in-Chief (EIC) of the journal Wirtschaftsinformatik. Introducing a double blind peer review process was certainly an important hallmark of establishing a state-of-the-art quality assurance process. In addition to reviewing many papers for the EIC, I was able to observe that introducing an internationally proven quality assurance process was anything else but easy. Wolfgang Koenig made it happen. He also wanted to open the Wirtschaftsinformatik journal to an international community. But the publishers and some colleagues repelled this since they expected a negative impact on the subscriber base. Corporates held almost three quarter of all subscriptions and their IT managers were considered to prefer German as a language for the periodical. It seemed impossible to manage change towards internationalization. Money talks - no budget was made available by the publisher. Nevertheless, Wolfgang Koenig managed to include Wirtschaftsinformatik in the International Scientific Indexing (ISI) impact factor list since he was able to appoint several international editors to the journal. The dawn of internationalization was on its way. Co-editor Gerhard Knolmayer played a pivotal role in advocating this move.

\subsection{Birth and Transformation (The Past)}

In 2006, Hans Ulrich Buhl took over and pursued his wellarticulated triple strategy. The idea was to divert practiceoriented research into the WUM (Wirtschaftsinformatik \& Management), whereas academic content was continued to be published in Wirtschaftsinformatik. The latter itself was re-launched on a bilingual basis: all submitted and accepted manuscripts were published in German and English. There was an ardent and passionate discussion about the English equivalent of the name Wirtschaftsinformatik. The EIC pushed the discussion towards two dimensions. Since "Business Informatics" was perceived to be not wellestablished, the name selection process was anything but easy. "Information Systems" as the key research object signaled an attachment towards the Anglo-American Community. The noun "engineering" deliberately heralded 
a more technology-centric approach and "business" marked the domain of technology use. Thus, Business and Information Systems Engineering (BISE) was born.

To facilitate change, Hans Ulrich Buhl raised a six-digit amount of Euros (a seven-digit amount in more than 10 years) to provide complimentary translations for successfully deploying the internationalization strategy and to increase the economic degrees of freedom towards the publisher. Money talks. Most translations were conducted from German into English, thus offering a valuable service for further nudging the entire community which had been able to pass its first international journal list shortly before. The task force of WKWI and GI FB WI (formerly GI FB 5) had been able to ratify an international journal and conference list (Heinzl et al. 2008) after a passionate debate at the Wirtschaftsinformatik 2007 conference in Karlsruhe. Together with Guenther Mueller, Robert Winter and myself, Hans Ulrich Buhl streamlined a powerful operational backbone of the BISE journal with a clear contentcentered division of labor, but without implementing a department system. In parallel, the publisher reorganized its operations processes and deployed a novel editorial system whilst relocating most production activities to India. Despite my own background in IT outsourcing and offshoring, I was stunned by the multifold cultural experiences and incidents that this triggered. We should have written a paper about it.

\subsection{Expansion and Perfection (The Present)}

In 2012, Martin Bichler took over the position of the EIC. My former student colleague Robert Winter and I got alleviated to Vice Editors in Chief (VEIC) whilst forming and running editorial departments with appreciated colleagues. Martin Bichler's major move was the transition into a department system and the sole focus on English as the journal's lingua franca. The core idea was to organize the journal around established sub-communities in order to foster high-quality submissions. This, in turn, was inevitably intertwined with a pluralistic approach regarding the communities' research domains and research methods. Despite some memorandum efforts, pluralism has been the key. The outcome of this strategy is still prevalent in BISE. It can be found in the Editorial Statement (Bichler 2018a) of our journal. To further stimulate internationalization with a strong European background, we were able to convince Wil van der Aalst to succeed Robert Winter as a new VEIC in 2016. With a strong background in BPM and analytics, he was the perfect candidate for this role and pushing the boundaries further.

To continue the journey towards internationalization, the idea was to deploy at least two internationally recognized scholars per department as editors: one from the
German-speaking countries and one from other nations, preferably from Europe. In order to achieve this, we were willing to accept that some of the departments had an asymmetric division of labor. Operational excellence and new intakes based on international reputation had to be balanced. The idea was to foster the role as flagship journal for the entire German-speaking community, but at the same time create an internationally recognized brand with a strong European identity that offers a platform for those communities that do not perceive behavioral research as the sole hallmark of their research. Short cycle times in the reviews were pushed further to offer an additional element of sustained differentiation. In this context, the flaws and incidents of the initially cumbersome processes with the editorial system from overseas have been reduced, professionalizing the division of labor between continents. Content generation was effectively catalyzed and managed out of Germany, then released and handed over to India, where it was finalized and published. My deep gratitude goes to Martin Bichler and his team who perfected BISE on this next level.

As the journal was an early mover with special issues for emerging topics, structured literature reviews on contemporary themes as well as catchwords were accelerated. The outcome was notable. The ISI 5-year Impact Factor reached 3.586 (see "BISE in numbers" in this issue). The journal was admitted to the ERIM Journals List, which further increased visibility in Europe. This journey made BISE the most successful international scholarly journal in the German-speaking domain of business administration while other formerly renowned outlets like the DBW vanished from the scene since they did not (attempt to) manage the transition (Kieser 2012, 2016). I have been told that envy is likely to be an honest form of anchor recognition.

However, my sincere recognition goes also to Ulrich Hasenkamp who has been the guarantee for the journal's operational continuity since Paul Schmitz' tenure. From 1992 on, he acted as Co-EIC with Peter Mertens and has been as the soul for perfecting BISE's pre-production since 1984. That's more than 30 years of incredible academic service for BISE.

\subsection{Aspiration and Nexus (The Future)}

Nevertheless, the journey towards a renowned international journal with a strong European background has not yet reached the final stage. The point of departure, however, has changed. After receiving more international recognition, BISE is now less in the position of the hunter but increasingly in the role of the hunted. Thus, our journal is now on the radar of competing outlets and other international communities. Evident success concepts are likely to 
be adopted by other journals which raises the question what the source of sustained competitive advantage (Mata et al. 1995) should be for the future. I am convinced that two attributes cannot easily be adopted by other outlets: disciplinary pluralism and technology orientation. To be more precise, technology orientation may cause more substantial, i.e. more relevant ways of conducting managerial research. And technology orientation is something that cannot be immediately adopted by competing outlets. Thus, we should further go for it.

The next incoming EIC, Christof Weinhardt, acknowledges flow and diversity as continuing key pillars of the future strategy of BISE (cf. the last part of this article). Fully agreed! Furthermore, he conventionalizes participation as another important element without developing a programmatic agenda. Interestingly, participation reveals proximity to the open research paradigm proposed by van der Aalst et al. (2016a). The following options prevail:

(1) Participation in academia could be increased by disclosing all reviews and reviewer names after the review process is over. Publishing the names of the reviewers could be considered as a token for appreciation and, thus, increase participation (e.g., Ross and Boshoff 2017 or Urquhart et al. 2018). Publishing the reviews fosters the academic discourse quality and may reveal useful insights which enable younger scholars to learn from good examples.

(2) BISE should continue to emphasize being a nexus for real-life problems. The demand for academic rigor makes publications cycles very long and often disconnects them from real-world problems. Thus, we should think of new formats like an idea market for novel research problems fueled by practitioners, practitioner ratings regarding the relevance of published BISE papers on the web, practitioner downloads, or publishing technology-centric research and teaching cases. BISE must find new ways to reconcile industry and academia on a top-notch scientific level in novel participative ways. This may help to actively master the pivotal challenges of digital transformation and to increase participation of practice.

(3) Another consequence for the future would be to establish a non-German-speaking EIC. The proclaimed European notion will have a rather limited scope if BISE does not change with respect to its idea of leadership. Does BISE want to become a truly international journal or does it want to remain a journal from the German-speaking countries with some European flavor? Presumably, future EICs should be recruited from (younger) DEs who were able to prove their value potential to the journal.
Thus, international participation is another source for developing BISE further.

(4) Younger scholars are well advised not to follow the mainstream. They should publish parts of their research and accept editorial positions at BISE. Doing so is probably more burdensome than accepting roles in mature outlets but offers the opportunity to make a difference. I had plenty of chances to serve at internationally established journals but I deliberately decided to make additional efforts and take reputational risks. Don't go for the mainstream, go for the "newstream", i.e. make the difference! It offers richer opportunities for shaping and framing new themes and structures. Furthermore, taking the longer way will acknowledge and appreciate the vast efforts of those dozens of colleagues who have offered sweat and tears for BISE in the past.

I feel that the time is right to handover more roles and responsibilities to younger scholars with new ambitions and ideas. Although not everyone can be a figurehead, many articulated minds and invisible hands are required to push BISE up to the next frontier. As we have learned from Adam Smith (1776), the invisible hand is a metaphor for how ambitious individuals operate through a system of mutual interdependence to promote the general benefit of a community at large. I wish our BISE all the best to further thrive and prosper - from an invisible hand to hopefully many future invisible hands.

Prof. Dr. Armin Heinzl

University of Mannheim

\section{Trends in Information Systems Engineering: Recurring and Emerging Questions}

\subsection{Sixty Years of History}

The journal is now known under the name Business \& Information Systems Engineering (BISE), but had different names in the past (Hasenkamp and Stahlknecht 2009). BISE started with the name "elektronische datenverarbeitung" and was founded by Hans Konrad Schuff in 1959. In 1971, it was renamed to "Angewandte Informatik" to reflect the broadened scope of the field (not just data processing). However, because of spectacular developments in Information Technology (IT), many specialized application domains emerged (e.g., medical informatics and production automation). Therefore, the scope was too broad and the journal was rebranded into Wirtschaftsinformatik in 1990. Although the journal was successful for a long period, it became evident around 2005 that it would be difficult to maintain Wirtschaftsinformatik as a scientific journal with 
articles in German. German-speaking practitioners were less interested in rigorous scientific articles, and Germanspeaking scientists did not want to limit their audience to German-speaking countries. Therefore, on the occasion of its 50th anniversary, Wirtschaftsinformatik was complemented by an English version of the journal: Business \& Information Systems Engineering (Buhl et al. 2012c; Buhl and Lehnert 2012). Initially, the journal was available in both English and German (2009-2014). Since 2015, BISE is published only in English. Looking at the submission numbers and impact of the published papers, it was a very good decision to make the journal truly international.

In the remainder, we reflect on 60 years of history. On the one hand, the field has changed dramatically. Note for example the way we think about "open research", i.e., open publications, open reviewing, open data, and open software (van der Aalst et al. 2016a). On the other hand, some of the challenges identified decades ago remain demanding and exciting at the same time. First, we discuss general developments in Information Technology (IT). Then we highlight a few recurring questions in information systems engineering. Finally, we discuss the need to make information systems engineering "responsible". The common expression "With great power comes great responsibility" already reveals that increasing capabilities and added intelligence lead to new challenges. BISE can play a role in providing information systems that protect people from negative side-effects of our "great power" to process large amounts of data.

\subsection{Developments in Information Technology}

Taking a step back and looking at the 60-year period in which the journal has been operational (1959-2019), one can see that several main developments have been ongoing for decades. Here we mention a few.

\subsubsection{Reduced Distance Between IT and Reality (People, Machines, Organizations, and Society)}

Initially, computers were huge and could perform only very specific tasks. Today, we carry mobile phones, share our mood via social media, and walk through a world loaded with sensors. The quantified-self movement, also known as lifelogging, illustrates literally the reduction in "distance" between Information Technology (IT) and the real world we live in. Amazon can only sell a book when the website allows for it. When flying, one no longer gets a paper ticket. In an airport, every move of a suitcase, from checkinto the loading into the plain, is monitored. In production, different components have a unique id. Eggs in a supermarket are also uniquely identified to trace them back to their origins. These examples show that there is a stronger alignment between the digital world and actual products, machines, people, organizations, etc. Whereas the PC (Personal Computer) was not so personal, our smartphones have become digital companions. Similarly, enterprise information systems have become digital shadows of organizations.

\subsubsection{Moore's Law (Faster, Cheaper, and Smaller/Larger)}

Fifty years after the formulation of Moore's law, processing and computing power continue to grow exponentially. Moore's law initially referred to the periodic doubling of the number of transistors on a chip. However, the same principle applies to all kinds of storage, processing speeds, the number of pixels, network capacity, etc. Although this has been an ongoing phenomenon, its effects are disruptive at particular points in time (like a bucket suddenly overflowing). Consider for example car navigation. Iter Avto was the world's first automobile navigation system and used already in 1930. Predecessors of today's GPS were up and running in the 1960s. However, only in the 1990s car navigation systems worked well enough and were sufficiently affordable to be used on a large scale. Hence, the breakthrough of car navigation is directly linked to Moore's law. The same applies to speech recognition. Siri (Apple), Alexa (Amazon), Cortana (Microsoft), and Google Assistant are based on old ideas that have suddenly become feasible because of the increased (affordable) computing power. We will see similar breakthroughs when it comes to robots, autonomous driving, etc.

\subsubsection{Encapsulation of Functionality (Modules, Components, Services, and the Cloud)}

As our capabilities to process information increase, we tend to use IT for more complex tasks. Modern cars, for example, have become rolling computers. Most cars have over 50 computer systems monitoring and controlling everything from the engine and ride handling to on-board entertainment and communication. To tackle the growing complexity, big systems are broken down into parts and functionality is "outsourced" to parts with a well-defined interface. Modularization is the key principle. Components and services are terms referring to the same principle. Apart from encapsulating functionality, processing and data storage can now be handled at the most appropriate location. For example, cloud technology allows for sharing computing resources and providing the same service at any location. 


\subsubsection{Added Intelligence}

AI normally refers to "Artificial Intelligence", but many argue that "Added Intelligence" would be a better term. Computers can do more and more tasks autonomous and can perform work traditionally done by humans. The goal is not to replace people, but to support them. Automated data-driven decision making is present in many of today's systems. It started with decision support systems that were fully programmed by people. Today, machine learning techniques make decisions that are not programmed, but that were learned based on historical data.

\subsection{Recurring Questions in Information Systems Engineering}

The four main developments help to put 60 years of BISE in perspective. Interestingly, there are a few recurring questions that can be found throughout the history of information systems engineering.

\subsubsection{How to Divide Tasks Between Humans and IT?}

What should be done by humans and what should be done by computers? This question was already there when the first computers were being developed. Computers are faster and more accurate when it comes to structured and predefined problems. Humans are more flexible and can deal with new and unstructured tasks. Currently, "semiskilled administrative jobs" (i.e., jobs requiring some form of training of education, but that are quite repetitive) like approving applications, cashing checks, and selling tickets are being replaced by IT solutions. Less (e.g., manual labor) and more skilled jobs (e.g., jobs requiring university education) cannot easily be replaced by IT yet (or this is not cost effective). Consider for example detecting skin cancer. Here, a hybrid approach currently works best (a first analysis is done by software and the final diagnosis is made by a doctor). Another example is the uptake of Robotic Process Automation (RPA). Automation aims to address the tasks that are most frequent. Less frequent tasks are not considered because automation is too expensive. Therefore, these are often handled manually by humans entering information repeatedly and making decisions. In such settings, humans serve as the "glue" between different IT systems. RPA aims to support the middle part of the frequency spectrum (between repetitive and ad-hoc) by having agents that interact with the different information systems as if they were human (van der Aalst et al. 2018).

\subsubsection{How to Relate Data and Processes?}

Another recurring challenge is the relationship between data and processes. State-of-the-art approaches like UML still have different diagrams covering different aspects, e.g., class models for data and activity diagrams for processes. These diagrams can be or are related, but this is often unclear or hidden. Approaches such as colored Petri nets fully integrate both but are not widely used and cannot be used to handle complex designs. In today's literature, one can still witness a continuous stream of new proposals to integrate both perspectives.

\subsection{Emerging Questions in Information Systems Engineering}

As sketched before, there are many questions that recur in different contexts as IT continues to develop. Therefore, these questions remain relevant for BISE researchers. However, there are also a few fresh questions that look at information systems engineering from a novel angle. One of these developments is that people have become aware of the negative side-effects of IT and call for "responsible information systems engineering". An example is Responsible Data Science (RDS), which centers around four challenging questions (van der Aalst et al. 2017):

- Fairness: data science without prejudice - how to avoid unfair conclusions even if they are true?

- Accuracy: data science without guesswork - how to answer questions with a guaranteed level of accuracy?

- Confidentiality: data science that ensures confidentiality - how to answer questions without revealing secrets?

- Transparency: data science that provides transparency how to clarify answers so that they become indisputable?

Although these questions are specific for data science, the concerns they embody also apply to information systems in general. For example, are information systems "fair"? How to define fairness, accuracy, confidentiality, and transparency notions upfront? Consider an information system as a means of (data) transportation. How to make such a transportation system "green"? Legislation can be used to provide incentives for innovation, see for example the General Data Protection Regulation (GDPR) introduced in May 2018. However, this is not enough. To make information systems "green" we need the equivalent of solar cells and windmills. This will be one of the main challenges for BISE researchers in years to come!

Prof. Dr. Wil M. P. van der Aalst RWTH Aachen 
4 Views on the Past, Present, and Future of Business and Information Systems Engineering (BISE)

60 years ago - in 1959 - the first issue of the journal elektronische datenverarbeitung (electronic data processing) appeared with the objective to close the gap in scientific research publications with respect to the "practical application of computers in business" (Schuff 1959, p. 3). Already then, the necessity of integrative thinking - which is constitutive for today's Business and Information Systems Engineering (BISE) - was clearly fixed in the minds of visionaries. E.g., in this very first issue, John Diebold (1959) pleads for well-founded university education and extra training alongside work in the field of BISE and argues: "If [the businessman] uses the new machines of automation just to do more rapidly tomorrow that he is already doing today, he will not have to come to grips with the problem; worse, he will have let slip the largest opportunity of his business lifetime". Karl Heinz Kettner (1959) also postulates the use of information and communication technology to enable integrated workflows and to make enterprises more competitive.

In those days probably neither the editorial staff nor the publisher or the readers expected that this journal under the name of Wirtschaftsinformatik would advance in the next 60 years to the most important scientific journal of this young field in the German-speaking countries and, under the name BISE, gain a lot of international reputation in the last 10 years. I feel honored to be invited to this anniversary issue and I am happy to contribute some experiences and thoughts on the past, present, and future of BISE.

By the time I took over the duties as Editor-in-Chief from Wolfgang König from 2006 onwards, the enormous efforts towards the improvement of scientific quality were already bearing rich fruit. Thus, the journal Wirtschaftsinformatik was one of the few German-speaking journals included in the Impact Factor by Thomson Reuters. In 2008, it was ranked as the best German-speaking business economics journal in JOURQUAL, the official ranking of the German Academic Association for Business Research (VHB), evaluating more than 1600 international journals. Despite these strong points and the success in the Germanspeaking area, the journal Wirtschaftsinformatik was faced with a dilemma.

On the one hand, universities in German-speaking countries - parallel to many other countries - took their bearings for the appointment criteria of professors in accordance to the long-established custom in North America, and thus relied on publications in highly ranked, mostly English-speaking journals, causing the pressure to publish to increase greatly, especially for upcoming researchers. Due to the lack of an internationally renowned journal for the publication of design-oriented research, more and more authors turned to research methods favored by internationally established journals in the field of Information Systems. As a result, the number of submissions decreased, even though the scientific quality of the journal rose.

On the other hand, the published papers became increasingly cumbersome to read for practitioners due to the rising requirements for scientific quality (Buhl et al. 2012a). Much effort was taken not to lose the readership from practice. Nonetheless, a relatively slow but continuous loss of subscribers could not be held up in an environment of generally shrinking markets. The journal boasted more than 4000 subscribers in its prime, but the balancing act between highest scientific quality and the wants of practice became ever more difficult to perform. Apart from these developments, criteria for success issued by the publisher changed considerably at the time. For instance, download numbers and world-wide digital distribution of the journal gained in importance in the context of increasing digitalization.

To meet these challenges, on the occasion of the 50th anniversary and after fruitful discussions with the editors and the publisher, it seemed obvious to strategically reset the journal's course, to align the journal with the increasing importance of international research, to establish a unique platform for our rather design science-oriented research, and to address all techno-economically oriented readers and authors. Thus, 10 years ago, we launched the comprehensive, bilingual triple-strategy addressing both researchers and practitioners. We intended to transfer the advantages of the journal Wirtschaftsinformatik and its topics for the German-speaking area to the international area by means of its English-speaking twin issue BISE, which was published via SpringerLink and for 6 years appeared simultaneously, with identical content to the German print journal Wirtschaftsinformatik. This strategic realignment was only possible due to the generous support of our industry partners Allianz, Commerzbank, Deutsche Bank, IBM, McKinsey, SAP, and T-Labs who contributed more than $€ 1$ million in the last 10 years for the journal's internationalization and digitalization strategy. Only with the help of their support, for example, the one-to-one translation of the German articles of Wirtschaftsinformatik into English became conceivable. Without the relentless commitment of Ulrich Hasenkamp and his team in Marburg the bilingual issue of the journal could not have been accomplished. For all this and the active support in designing and implementing the triple strategy I express my grateful thanks.

At the same time, the Wirtschaftsinformatik \& Management (WuM) was supposed to address the readers from practice. WuM inherited the practitioner-oriented sections of the scientific journals, developed them further, and 
provided management summaries of research papers. The connection between industry and academia has been further strengthened by the fact that subscribers have access to all online archives, no matter which of these journals they obtain in print.

The general aim of the strategy was to link tradition and future, to combine rigor and relevance, and to stabilize the number of subscribers from science and practice through a clearly target-oriented strategy [for an extended history of the journal, cf. (Buhl et al. 2012c; Hasenkamp and Stahlknecht 2009)]. This aim was also the guideline for all efforts to unite rather than separate the German-speaking community with the twins Wirtschaftsinformatik and BISE as its central publications.

A major question in the course of this triple strategy was the one concerning an appropriate title for the Englishlanguage issue and the connected key messages. With BISE we convey the design science approach via the term "engineering". Moreover, we signalize that we address all techno-economically oriented readers and authors as target groups. By means of the term "business" we address colleagues who approach BISE questions from a more business administration perspective. With "information systems" (IS) we reach the growing number of international IS colleagues who are interested in both rigor and relevance. With "engineering" we additionally address German- and English-speaking industrial engineers and colleagues of applied computer science who deal with BISE-related topics. The title's ambivalent reading addresses economically oriented (business and business engineering), IS- and BISE-oriented (information systems and information systems engineering), and engineeringoriented (business engineering and information systems engineering) readers and authors, the disciplines' borderlines, and thus the entire techno-economically oriented scientific community.

The triple-strategy's primary objective was to position the new journal as one of the international top journals, by conveying the field's and journal's strengths to the international world without neglecting their position in the German-speaking countries. These strengths are the fruitful and mutual exchange with business practice as well as the pluralistic, rather design science-oriented, and interdisciplinary research approach. The former becomes particularly evident in the fact that at most economic faculties BISE departments are the largest ones and those with the highest amount of third-party funds by conducting projects solving problems in the real business world with high relevance.

Good scientific BISE publications not only fulfill rigor, but also relevance criteria of a high standard. To achieve that, each manuscript is pre-reviewed by the editor-in-chief with support of highly skilled colleagues. If promising, manuscripts are evaluated - usually after a first revision by at least three international experts from science and practice (usually there are two from science and one from practice) in multiple rounds to publication maturity. Involving reviewers from practice also shows the significance of relevance. What we aspire is to extract the scientifically interesting core and to identify valuable contributions by constructive suggestions in the sense of "journal editors as diamond-cutters rather than gatekeepers" (Straub 2008, p. vii). This method avoids type II errors ("rejection of a valuable contribution"), which have been discussed by Detmar W. Straub (2008) and Carol Saunders, the former editors-in-chief of MISQ.

Another strength of BISE is the university education: By means of an interdisciplinary orientation at the borderline between science and business practice, BISE graduates are highly qualified for further activities in both science and practice. Thus the demand for these graduates is high. It is not unusual that enterprises get involved financially and/or by means of additional courses (e.g., project seminars) in many BISE study programs in order to get to know later graduates and highly qualified students at an early stage. Consequently, these excellent career perspectives make BISE highly demanded by school graduates.

Therefore, I argued that BISE has reasons to not only overcome its weaknesses but also to further improve its strengths in a self-confident way and by no means to sacrifice these strengths on the altar of a misunderstood international adaptation.

6 years later, I could report in the last issue 2013:

- By combining the German-speaking Wirtschaftsinformatik, the English-speaking BISE, and the practiceoriented Wirtschaftsinformatik \& Management (WuM), the downward trend in the number of submitted papers and of subscribers could be stopped.

- In the first half of 2013, the number of downloads of Wirtschaftsinformatik had risen by more than $500 \%$, compared to the first half of 2008, the year before the strategic re-orientation. For the further development, see the information box "BISE in numbers".

- By the end of the year of BISE's introduction, downloads rose to a level of $75 \%$ of the number of downloads of Wirtschaftsinformatik in 2008, its 50th year of existence. In the first half of 2013, they had risen by a further $800 \%$ compared to the first half of 2009.

- All in all, articles in BISE/Wirtschaftsinformatik are meanwhile downloaded more than 12.000 times per month.

- With respect to journal impact factors, which mark an internationally still significant success factor for scientific journals, although this is subject to critical 
discussion (Buhl et al. 2012b): Since 2007, the impact factor of BISE/Wirtschaftsinformatik rose by more than $300 \%$ to 1.200 in 2012 , considerably more than all competing journals.

- However, we so far have not managed to pile up a backlog of fully accepted papers published "online first" due to the constantly low acceptance rate slightly below $20 \%$.

- Thus the continuous rise of submitted papers remains an important aim which can only be met if both the German-speaking BISE community and the Englishspeaking IS community, respectively, increasingly submit their best articles to BISE/Wirtschaftsinformatik.

Due to the excellent work of Martin Bichler and his team, who took over the content responsibility as of January 2014 , not only the latter and much more could be achieved (see the information box "BISE in numbers"). The Scopus Citescore increased to 2.54 in 2017, which is 5 times the score of 2011. In the same period the citation metrics of the North American top journals MIS Quarterly (MISQ), Information Systems Research (ISR), Journal of Management Information Systems (JMIS), and Journal of the Association of Information Systems (JAIS) varied only slightly.

I was and still am glad to see that the journal has not only consistently continued, but also doubtless successfully advanced with fresh ideas in the last years and am confident that this will continue in the years to come.

In 2007, as discussed above, the prospects of the solely German-speaking Wirtschaftsinformatik appeared dim and even the worst case of losing not only contact with international standards but also the support of the publishers seemed possible. This trend was turned around and positive developments were made possible by introducing the triple strategy in 2009 and by the combined efforts of the entire community.

Despite the success in the last 10 years discussed above, we still have a long way to go in the years to come to establish the journal solidly in the high-end position of the international journal environment. For this, I express my best wishes for future success to Christof Weinhardt and his team in the same way he helped Martin Bichler and myself in the last 12 years.

And finally: The success of the last 60 years was only possible because of the commitment of all members. This also applies to the journal in the future. Therefore, I would kindly like to ask all of you for your support to positively develop this strategy further together with the new editorial team, to multiply it in your personal networks, and thus to make it become well known. Only then will we succeed nationally and internationally also in the future!

Prof. Dr. Hans Ulrich Buhl University of Augsburg
5 In the Two Decades Around the Year 2000, our Discipline Wirtschaftsinformatik and our Journal Wirtschaftsinformatik Became - Closely Aligned to Each Other - Mature

I had the honor to serve 10 years (until 2008) as EIC of the Wirtschaftsinformatik (our journal's name then) - and the decades around the millennium were important for both our journal and for us as the German-speaking academic community Wirtschaftsinformatik. Fundamental changes and adjustments had become increasingly necessary - for instance because of the ever-increasing internationalization also in the social sciences -, and between 1985 and 1995 two research support programs of the German National Science Foundation (DFG) for our discipline Wirtschaftsinformatik literally "kicked off" this transformation. (I beg the Austrian, Swiss and Liechtenstein colleagues' pardon: In those times I did not take sincere notice on their respective research support programs for our discipline - the other German-speaking countries also looked out for their chances, and they were more than once more successful than we in Germany. And of course, their success also helped us all.)

My central conjecture is that both - our community as well as our journal - (aside from some flaws which of course occur when such substantial changes have to be performed) truly accepted and really positively met the requests of close cooperation and interaction - and both succeeded in (as we Information Systems scholars would say) aligning the discipline and the journal developments closely and mutually pushing each other forward, thus transforming both in a kind of lockstep into a new "orbit" which can be labeled with three aspirations (see the following sections).

\section{1 (The Challenge of a Systematically Fledged) Internationalization}

At the end of the 1980s, we had a rather limited international exposure of German (speaking) Information Systems academics and their research results, in particular with regard to the US. To give our readers today a better feeling of the state of internationalization in our discipline, let me recall an occurrence during the 1991 ICIS Conference in New York. We just had successfully finished the first DFG research support program and were asked by evaluators to substantially increase the visibility of German (speaking) IS research results in acknowledged international journals and conferences.

So, (at least for us as young academics) as a first step to better get to know the international habits and the respective colleagues, we attended this highly renowned conference. Of course (as we knew afterwards), the conference 
organizers ${ }^{4}$ would not have changed their regular procedures just for letting us present recent findings, but they set up a kind of a panel discussion (with another topic) in which we were "integrated" and that was headed by a German colleague who - words that he used then (please allow me to not disclose his name here) - had "fled" to the US (and became there one of the hot shots of the IS discipline). Why had he left? Because he could not stand the German style rope system ("If you support my "promising" scholar, I support your "promising" scholar").

In short: For him, it was a session of reckoning (for me it was a nightmare, because I suspected that he was not the only one with such thoughts). We barely talked about our research findings (which - given our then common way of thinking and presenting -, with a high probability would not have passed their quality gates, at least not on the first try), but we were literally - coram publico - flooded with severe deficiency accusations of the traditional German academic system, such as: German chair holders barely do research by themselves but use findings of their assistants (without crediting them); German professors fear that their assistants overtake them research-quality-wise and thus hinder them; a lot of German researchers are not aware of the actual international front line of theoretical work, they thus cannot perform high-quality peer reviews of other articles; and so on. I estimate that overall at that ICIS conference, there were two accepted presentations of research results from Germany (out of, probably, 80), and we had around 10 German participants (out of, probably, 1.000) - and this "low" was sustained. Looking at topnotch international journals in those times, we can conjecture that the picture there was even gloomier.

This situation has since then changed substantially (of course not only as results of our own decisions and actions). And clearly: This change was the result of aligned interactions of both our journal and the German (speaking) academic community - i.e., the ever-increasing quality of research contributions of our esteemed authors. Before we elaborate on that, let us look at the development of our journal Business and Information Systems Engineering (BISE) which is now almost 60 years old. Our journal started with the name elektronische datenverarbeitung (electronic data processing) in 1959 - then being driven mainly by academically interested practitioners (as there was not yet an academic discipline - its start should take another decade). The main focus then was the description of interesting application cases for the rapidly developing information technology - and there was no topical restriction (the confinement to Business and Economics came after 3 decades). 10 years later the journal changed

\footnotetext{
${ }^{4}$ Please bear in mind: In those times we communicated with the program chair by exchanging "yellow" letters.
}

its name to Angewandte Informatik (Applied Computer Science) and complemented its oeuvre on the academic side, for example, by handing over the leadership to a successful practitioner who was working as a University Professor, Norbert Szyperski, and introducing a surveytype of articles that collated and curated other articles on a particular research and application subject (using a kind of generalized evaluation pattern). In 1990, the journal was again renamed - now into Wirtschaftsinformatik (literally translated: Business Informatics - which for some colleagues does not sufficiently reflect the engineering strand of our discipline). This transformation was closely connected to my predecessor as EIC Peter Mertens, a highlyreputed University Professor of Wirtschaftsinformatik. We now transformed to a journal that focused on IT applications - only - in Business and Economics, and the journal developed into a central organ of the rapidly growing (German-speaking) Business Informatics academic community (actually: it was now the academic leadership that actively involved practitioners). Moreover, in the beginning of the 1990s, the German (speaking) Wirtschaftsinformatik community became member of the Association of Information Systems (AIS), the world head organization that comprises respective national head organizations for Information Systems (as it is named) academics (and that runs the ICIS conference series). And in the eyes of critics, AIS seems to overly emphasize the Business/Economics orientation - and thus rather one-eyed furthers the advancements of social sciences.

\subsection{Double-Blind Peer Review, Science Citation Index Expanded Participation, and Change of the Basic Culture of our Journal and thus of our Discipline}

Until, say, the first half of the 1990s, we presented ourselves in the Wirtschaftsinformatik completely in German which also included that we - following our legacy - did not employ a double-blind peer review system (as it was likewise the case in all important Business Administration and Management oriented German journals). Research articles were repeatedly of the type "how I did it" and "my opinion is", and we seldom had an interview with an internationally renowned colleague in English. And also in this tradition - and, please, without any sense of complaint (but nowadays we have to clearly identify the respective sources and roots ...) - the basic culture of our journal was not to primarily promote theory and methodological advancements (ideally proven at least once practically successful in a reasonable use case), but to a large extent to satisfy the (alleged?) requests of practitioners when using new IT. After some (time-consuming) initial steps to increase the academic quality of research articles, around half of each issue was filled with (pretendedly) easy-to- 
comprehend information in the real application world or with personal news. My perception is that (in those times), say, 150 researchers were "not unimportant" compared to, say, $1.500+$ practitioners that subscribed the journal - but with respect to the real decisions the traditional part of the scholars just liked that argument of the "large (practitioner) customer base" very much. And thus we must admit that in those times (aside from rare exemptions, which prove the correctness of the statement) the - substantial - Germanspeaking research capacity in Wirtschaftsinformatik did not sufficiently contribute to the internationally shared research advancement of our discipline - instead, we largely worked in two parallel strands (following in parts rather different ways of thinking and acting); and the German (speaking) Wirtschaftsinformatik came under pressure.

Thus, we for instance adopted (though only after more than one unsuccessful try) the double-blind peer review in 1998. Later, the Wirtschaftsinformatik also became member in the Science Citation Index Expanded community. Moreover, we stepwise extended the board of editors of our journal by - roughly $-15 \%$ to employ renowned international colleagues. We wanted to signal to the outside world that we invite submissions from the English-speaking world and can cater for their evaluation - not only from a German (speaking) point of view. But this advancement did not pay off as expected (as the number of international submissions remained rather low) and this was one of the reasons to then - in 2009 - profoundly change into an English-language journal.

It is in the realm of our leaders today to count and to comparatively rate - but, just as an indication: In last year's ICIS conference in Seoul, the German (speaking) countries gave roughly a third of all presentations of research findings (and that is the massive contribution of all the authors, also of those who did not make it into the conference) and the percentage of German-speaking participants also went up to - say $->25 \%$ (and, again, this is not a onetime shot, but a sustained development). To sum it up: Our journal has shaped our community and vice versa, and we are grateful that we had the chance to align our transformation with the transformation of other disciplines and journals.

\subsection{How to Retain and Sustain Our Regional Advantage in the International Competition?}

Yes, I also believe that we German-speaking countries overall often enjoy (in numbers) more and wider and richer interaction channels between academia and business practice - the engineering strand of Wirtschaftsinformatik is still working well. And yes, our close relations between academia and business practice have been probed more than once in the described course of fundamental transformation. But an extended set of accompanying changes in the realm of the journal (and again: presumably also in the culture of our discipline) has helped confine the negative effects of this change with respect to business practice.

We have for instance enlarged the editorial board around the millennium by $25 \%$ to include research-oriented practitioners in order to involve representatives (experts) of the relevant application industries there (with the aspiration to have each submission be evaluated by two academicians and one practitioner). My conjecture is that, against the backdrop of the German-speaking community being on its best way to become well-accepted in the international publication top scene, we are increasingly capable of putting (again: now also on the international side) more emphasis on complementing outstanding research results with more thoroughly tying-in the thinking and experience of appropriate practitioners in our research endeavors. As an example: Nowadays we often hear that data has the role which oil had for the world development in the past. Exactly this data could be cultivated as a linchpin between IS or Business Informatics academic analysis and the respective business practice. Of course, this data should be (and can be) profoundly anonymized, and of course such exchanges must be based on mutual trust. But then research-oriented practitioners could help (young) scholars to pinpoint highly interesting research questions and help them with data access, whereas the researchers help the practitioners to better analyze data sets and provide them with research-based advice on complex decision matters in practice. Then we could enter into a higher "orbit" of between academia and practice - aligned research - to the increased benefit of both sides - internationally.

\section{Prof. Dr. Wolfgang König}

Goethe University Frankfurt

\section{BISE Anniversary: A Statement}

A professional journal is subject to current practices and trends in the field. Scholars need to keep an eye on conventions, goals, and criteria of national and international science policy, as well as of public and private employers. Which achievements and other attributes are given most weight in position offerings and appointments? What types of studies and methods are preferred in the particular field (e.g., literature surveys on the state of the art versus conceptual studies versus empirical work including experiments as well as case studies on best practices and major failures versus development of IT artifacts and algorithms versus comments on national laws and political notions of 
intent)? Academic researchers and staff of R\&D departments ask for reliable data and clear evidence; practitioners require research reports that should be as neutral as possible, meaning that successes and failures - along with critical success factors and limitations - need to be described; publishers look at the range of services offered by competitors and assess their performance in different channels (e.g., print vs. electronic media).

Because of these manifold goals, being responsible for an academic journal is anything but an easy job.

It is against this backdrop that my successors as Wirtschaftsinformatik/BISE editor-in-chief decided for a paradigm shift by giving high priority to gaining a good position in the "international publication competition." In other words, they changed the journal's "center of gravity" to one that was common in many but not in all fields. Acknowledging this decision as a fact, I think that the BISE journal is professionally organized and managed.

Nevertheless, a leading academic journal can, and should, also influence the field of study by raising researchers' awareness for important economic and societal problems ("demand pull"). In this regard, one course of action would be to publish special issues on selected topic areas. And this is where I would welcome a change of emphasis. Specifically, in my opinion, the BISE community does not pay sufficient attention to challenges of information processing that organizations in the Germanspeaking area are currently facing. Some examples are listed below.

(1) Influential political forces ask for net neutrality of the Internet. Referring to net neutrality as a civil right in a democratic system, they argue that, for example, even sophisticated computer games that require considerable Internet capacity should not be assigned lower priorities than medical applications (e.g., real-time computer-tomography pictures) during a risky surgery. Proponents of efficient resource utilization, however, are likely to favor different net priorities, implemented in the switching nodes of the Internet. While computer science has already developed corresponding algorithms, Wirtschaftsinformatik could provide models of different compensation or market rules (Wirtschaftsinformatik is also an economic science!). A similar problem concerns the interorganizational exchange of data in (future) Industry 4.0 environments.

(2) In German-speaking countries, a major demand-pull results from the age distribution of the population. Following the polarization thesis, it can be expected that there will be a shortage of highly-skilled workers in the next decades and, at the same time, a surplus of low-qualified workers. Wirtschaftsinformatik could help alleviate this problem by advancing the development of assistance systems, thereby increasing the employment chances of people with relatively low skills. Examples include methods of real-time instructions.

(3) With regard to the public sector in Germany, the IT situation is precarious. If there were corresponding weaknesses in other (private) sectors and industries such as finance, tax consulting, energy, traffic, or health, members of the scientific community would publicly raise objections or propose solutions.

(4) With the number of critical incidents growing and disastrous IT project failures looming on the horizon, I started some analyses. The investigations took a lot of time and effort. Still, I did not send my results to BISE, as I anticipated reviewers arguing that the topic is not of interest to readers from other countries. I thus published my study results, as well as the results of a follow-up study that was finished 4 years later, in Informatik Spektrum. Both articles led to a series of presentations and discussions in different forums.

(5) For example, the collapse of the ELENA project as well as the 'solidification' of the P23R project are regrettable since both IT projects have been very interesting from a scientific point of view and also represented lighthouse projects of German Wirtschaftsinformatik.

(6) Relatedly, the extreme time delays and increased costs of the electronic health card project may be seen as a tragic malfunction of information management.

(7) Before new laws are passed, Wirtschaftsinformatik scholars should systematically check these laws in terms of whether they are appropriate for automatization ("Automationsgerechte Gesetzgebung"), and if not, appeal against them. A very important issue is the European General Data Protection Regulation. This approach would be more helpful than vague speculations on artificial neural networks in the public sector.

(8) A very contemplative example is the "virtual shrug" (and passivity) of the scientific community in response to the introduction of the IBAN, which arguably represents a quite unfortunate and unprofessional 'invention' in many respects.

(9) Up to now, the enhancement of management accounting, with the aim of evaluating the risky implementation and parametrization of Industry 4.0 systems from an economic viewpoint, has not been a 
matter of real concern to Wirtschaftsinformatik scholars.

Prof. Dr. Peter Mertens

University of Erlangen-Nürnberg

\section{Business \& Information Systems Engineering: The First 30 Years}

Sixty years is a long period for a professional journal. This is especially true for a journal that has to do with information and communication technology. And, even more, if today it is allocated in a scientific field which did not exist yet when the journal was founded. Being the journal's longest-serving officer (in different functions) I feel obliged to focus on the first half of the time frame, which is three decades.

The origin of the journal is closely connected to a company named mbp, Mathematischer Beratungs- und Programmierungsdienst (mathematical consulting and programming service). To be more precise, the company's CEO Hans Konrad Schuff was the driving force behind the journal for the first years until his sudden death. He was the visionary who was able to foresee the potential impact of the rapidly developing information technology on business. Nevertheless, the journal bore the name elektronische datenverarbeitung (electronic data processing), indicating the admiration of the technological platform, the "electronic brain". Looking at the content of the early issues, we find a mixture of reports on technical developments and on applications. Of course, some applications had a mathematical background (including operations research), but more remarkable is the number of administrative and managerial innovations that were reported or sketched out. Soon it became clear that the journal should not be classified as a practitioners' journal but was aiming at science. Remember - at this time, there was no academic field like computer science or information systems defined or even implemented.

When Schuff passed away at an early age, Paul Schmitz became a member of mbp's executive management and assumed the editorial function of the journal, after a few years and for a long time together with Norbert Szyperski. Several changes had occurred over the years, and some more can be attributed to Schmitz and Szyperski. Most importantly, the focus had narrowed down to applications. That is, mainly but not exclusively, business applications. Was it Schmitz' dislike of the word "electronic" in this context or other reasons that lead to a name change? After 12 years of "electronic data processing", the journal carried the name "Angewandte Informatik" (applied informatics) for many years to come. The interpretation of this name reveals the increasing focus on applications. However, "applied" is just an attribute! Obviously, informatics (or the American expression "computer science" which refers to hardware in its name) was the core. Moreover, the content of the issues to come shows that the journal did not exclusively deal with business applications but to a lesser extent also with other application fields (public administration, health care, engineering, construction, agriculture, art, etc.). Many articles cannot be categorized as either application or hardware oriented. Two big areas cover data bases and software engineering. From today's point of view, the graphical design of the title page is revealing: a pattern made of digits 0 and 1 strongly signals a technical background. What would have been the alternative? Up to today, there is no graphical symbol for applications that is intuitively understood.

The last issue under the name "applied informatics" (Nov/Dec 1989) is symptomatic of the subject mix. Of the eight papers, two deal with concrete applications in business and administration, two research papers take on a meta level for application development, two articles describe research on data bases and data dictionaries, one paper describes a software engineering aspect, and finally there is one study of hardware/system software problems. A detailed analysis of the journal's content is given in Hasenkamp and Stahlknecht (2009).

The evolution of the journal over the first 30 years corresponds with the academic environment. While Computer Science or Informatics had been introduced to many academic institutions worldwide quite early, the field of Information Systems or Wirtschaftsinformatik (Business and Information Systems Engineering) came up later. There was a big debate over the question if Wirtschaftsinformatik is part of Informatics or a research field on its own. In fact, this debate went on for more than the three decades and is partly still going on. For the journal, the upcoming self-confidence of the Information Systems community led to another name change after 31 years: Wirtschaftsinformatik.

The development of this branch of science took place in many countries simultaneously. However, elsewhere it was not quite as visible as in the German-speaking countries. Therefore, no other journals have been clearly dedicated to specific business information systems research. Fortunately, the foundation of AIS lead to the formation of a global community including conferences and publication outlets.

Looking only at the first three decades of the journal's existence, the majority of the papers were published in German, even those written by international researchers. Only the abstracts were translated into English. Amazingly, this barrier did not hinder the international acceptance of the journal, neither by readers nor by authors. The 
international breakthrough, however, occurred after the publication of a purely English version in later years.

To summarize, the current position of Business and Information Systems Engineering (as a field of science and as the journal) has evolved steadily, and the formation of the science is reflected in the development of the journal over the first 30 years of BISE.

Prof. Dr. Ulrich Hasenkamp University of Marburg

\section{Past, Present, and Future of Business Information Systems Engineering}

As the current president of AIS I want to congratulate BISE on its 60 years and continued success. The journal has gained a great reputation as one of the wide-ranging information systems outlets that allows for diverse views and research approaches. The current level of downloads and citations of articles in BISE demonstrate that it has gained a good standing first among German-speaking information systems scholars and later globally. It also shows how a strong community can build and sustain a strong scientific journal.

The community seems to have enjoyed its fair share of identity crises and soul seeking, and there have been calls for inclusion of more design into the mainstream (Österle et al. 2011) and calls for methodical pluralism (Loos et al. 2013). These debates are in my opinion a sign of healthy discipline. Furthermore, I see that we need different approaches more than ever. While much of our research is about the utility or efficacy of systems, there need also to be tests and expansion of boundaries of the possible through new designs and applications (Sein et al. 2007).

As computers have grown more powerful and software has matured, we have seen the rapid expansion of software into all walks of life. Growth of enterprise systems from mid-eighties until year 2000 issues marked an era of ever larger monolithic integrated systems. This was followed by the connection of systems across supply chains and networks. Now we see that the vast amounts of data created by these systems are analyzed and fused with sensor data (Jarke 2009). The next phase is the more advanced, and to certain degree artificial intelligence powered, analysis of the data and automated responses to business events based on the analysis. Despite the claims that AI will soon replace humans in coding and design, I believe that designers of the systems will still need some time. Even more importantly there is a need for critical analysis of what can be done, and what should be done, with the evergrowing information processing capacity. As an example, the juxtaposition of recent privacy breaches (e.g.,
Cambridge Analytica's Facebook data exploits and US carriers sharing of real-time user location with advertisers to name a few) against the new European GDPR approach to privacy should provide ample opportunities for the BISE community for the foreseeable future and even create new disciplinary topics, such as "Responsible Data Science" (van der Aalst et al. 2017).

Information systems development and modeling have always been central topics of BISE (Frank et al. 2014). I believe that as the interconnections of systems grow more complex, this area, together with executable models of service systems, will grow in importance. This is due to the fact that main technical hurdles (e.g., raw computing power, network speed and bandwidth) of digitalizing the enterprise have been more or less solved, and the emphasis in the next decade will be on making the software systems better, more user-friendly and easier to interconnect. This means that there will be a lot of opportunities for BISE as a field. Furthermore, it means that the emphasis moves from engineering the solution of technical hurdles to engineering user interface and cognitive issues. In other words, as bits eat atoms, it will mean good times for BISE researchers.

This expansion of digital information system leads to my last point for the future of BISE. The discussion on rigor versus relevance has been ongoing also in the BISE journal for a long time. I believe that we need to take relevance for a larger community more seriously in the future. This means that we have to understand the consequences of deploying systems and be able to reflect on them, in other words, we will need to see what happens on the last mile (Winter 2010). I do not share Nunamaker's view in (Winter 2010) that we are in a downward spiral, but I very much share the idea that we have to stay relevant through studies that seek to understand what happens when new ideas are put to practice. As information systems scholars operate in the junction between business (or government) operations and technology, we are uniquely well positioned to tackle the problems and opportunities that appear when new technologies and applications are taken into use. Furthermore, we have to stay vigilant and ask critical questions about the unintended consequences of new technology. I believe that BISE journal has rightly stressed relevance and real-world applications and that this will be even more crucial for the health of the discipline in the future.

I wish the journal, its contributors, readers, editors and reviewers continued success in the ever-evolving field of information systems!

Prof. Dr. Matti Rossi

President of the Association for Information Systems Aalto University School of Business 
9 Business Process Management: Past, Present, Future

\subsection{Introduction}

There are two fundamental perspectives on firms and their performance. First, the external perspective, as exemplified by the market-based view of Porter (2008), attributes the success of a company primarily to its competitive position. Second, the internal perspective, emphasized in Barney's (1991) resourcebased view, stresses the importance of the strategic resources of a company for maintaining a competitive advantage.

This latter perspective is strongly connected with the classical approach of Business Process Management (BPM), and prominently represented by the corresponding department of BISE. Business processes embrace all the relevant resources of a firm and coordinate them in such a way that they establish complex functional sequences. The activities of modeling, analysis, optimization, deployment, execution, and monitoring of these processes are integral components of BPM (Becker et al. 2013; Dumas et al. 2018), and they contribute to the success of companies today and will do so in the future.

\subsection{History of Business Process Management}

The history of the BPM domain started long before the initial mentioning of the term (zur Muehlen 2004). Its basic idea was described by Nordsieck already in the 1930s. In his work, he differentiates between the organizational structure and process organization. The structural organization is concerned with dividing the tasks of the company into task areas and defines roles and departments as entities that are responsible for these tasks. Such a structure is often represented with the help of an organizational chart. Regarding the process organization, he emphasizes that a company is, in essence, a continuous and uninterrupted chain of tasks. In this way, the process organization contributes to the overarching goal to optimally leverage available capacities, minimize processing times, minimize processing and throughput costs, and to design the workplace in a humane way (Nordsieck 1934).

In the subsequent decades, the structure organization received substantially more attention from research and practice. It was only in the 1980s when the focus started to shift, initiated among others by Gaitanides (1983) and Scheer (1989). Since Nordsieck, the electronic processing of business data had drastically advanced. For this reason, information technology emerged as a powerful tool to design business processes in completely new ways. At that time, also the term Business Process Management was coined and has remained until now strongly connected with capabilities of information technology to improve and innovate business. Indeed, the concept of BPM revolutionized the way how companies understand and perform work. Davenport's Process Innovation (1993) as much as Hammer and Champy's Reengineering the Corporation: A Manifesto for Business Revolution (1993) prominently illustrate the dramatic impact of BPM. Via this success, the process perspective has made its way into various areas that previously had no connection with BPM. A good example for this is the quality management norm ISO 9001:2015. In the past, the ISO 9001 standard was a pure handbook of norms. Since 2000 however, the ISO 9001 has adopted the process perspective, which integrates the application of typical BPM methods for quality management today (Becker et al. 2018).

\subsection{Business Process Management Today}

Since then, BPM has grown into a mature discipline with fundamental concepts and methods, such as the BPM Lifecycle (Dumas et al. 2018) and the six BPM capability areas (vom Brocke and Rosemann 2010), which structure the scientific discipline and give guidance for future endeavors. The BPM lifecycle describes the different management activities of BPM as a management cycle. It starts with the process discovery phase, which focuses on producing detailed descriptions of a business process as it currently exists. During process analysis, analytical tools and techniques are applied in order to determine weaknesses. Process redesign addresses the most important weaknesses and yields a redesign of the process. Subsequently, process implementation is concerned with the various steps of putting the new process into operation. In the monitoring phase, execution data are continuously collected and analyzed for their compliance with performance and conformance objectives. The six BPM capability areas cover the broader setting and organizational context of BPM projects and initiatives. First, the factor of strategic alignment calls for consistency between BPM activities and strategic objectives. Second, there is an emphasis on appropriate governance structures to establish BPM in a sustainable fashion. Third, BPM should be approached using sound methods. Fourth, it is recommended to consider the strengths of information technology to improve business processes. Fifth, any redesign measures should explicitly integrate the people that are involved and affected by the process change. Sixth, BPM should foster a culture that is supportive of change and improvement.

The BPM department of BISE has seen various important contributions to BPM research in the past and will further contribute to future developments of the field. The recent special issue edited by van der Aalst et al. (2016b) nicely showcases various latest contributions to a diverse set of BPM-related research questions. Still more recent works highlight the strong focus on methodological work 
in BPM, which concentrates on the development of new BPM methods and tools (e.g., Jouck and Depaire 2018; delRío-Ortega et al. 2017). The theoretical insights that stem from these models along with the developed methods and tools support the practical application of BPM in research and practice. Quantifying the effect and payoff of information technology endeavors has always been difficult, but by now, many successful BPM initiatives are documented within publications in BISE and applied collections such as the one edited by vom Brocke and Mendling (2018).

\subsection{Future of Business Process Management}

As pointed out above, BPM is true to its roots but is also moving forward. Surely, BPM will still play an important role when BISE turns 75 in 2033.

BPM is not a domain or method specific field, but continuously enables novel applications by means of technological innovation of concepts, methods or tools. Mooney et al. (1996) describe that these new technologies provide automation effects, informational effects, and transformational effects. Automation effects emerge when an organization uses a new technology to automate tasks that it previously did manually or with partial system support. Informational effects materialize from better tracking, monitoring, and analytical insights. Transformational effects relate to the changes in the mechanisms of coordination, which include disintermediation, outsourcing, or offshoring.

Four of the most promising new technologies in this context are process mining, robotic process automation, Industry 4.0, and blockchain. Process mining is the field that develops novel algorithms and techniques for analyzing business processes based on event log data (van der Aalst 2016). These event $\operatorname{logs}$ stem from various information systems that at least partially support the execution of business processes. Process mining techniques automatically generate business process models of how a process really works, compare process specifications with actual behavior, or visualize performance measures of the process. Process mining has matured to a level at which various commercial tools are available. It provides informational effects for better understanding business processes. Robotic process automation (RPA) is a technology that supports the automation of repetitive office tasks (Lacity and Willcocks 2016). It builds on so-called robots, which are software programs that interact with enterprise systems in a similar way to humans. The robots can gather data from these systems and update records by imitating manual screen-based manipulations. In this way, RPA provides automation effects for tedious office work. Industry 4.0 and the Internet of Things (Lee and Lee 2015) aim to support more flexible ways of working in a production setting. They build on sensor technology that is connected with so-called digital twins of the factory outline and of individual products. Digital twins facilitate the interaction with these physical entities in the real world as if they were software artifacts. In this way, Industry 4.0 provides both informational and automation effects. Blockchain is one of the recent technologies that has the potential to provide substantial transformational effects (Beck et al. 2017). Blockchain technology can be used to support the execution of inter-organizational business processes even in an untrusted setting (Weber et al. 2016). A rich spectrum of research challenges has been recently described by Mendling et al. (2018), both regarding engineering and management questions.

We hope to see many submissions to the BPM department of BISE on these and related topics in the future. BPM continues to be an exciting area of research!
Prof. Dr. Jörg Becker
University of Münster
Prof. Dr. Jan Mendling
Vienna University of Economics and Business

\section{Decision Analytics and Data Science: Past, Present, Future}

\subsection{Introduction}

For quite some time now, consultants not only in information systems speak about optimization. As a matter of fact, they usually do not mean optimization but improvement; and sometimes they use the word when they only mean change. INFORMS, the (US American based) Institute for Operations Research and the Management Sciences, successfully used the slogan "Science of better" for a number of years. In summary, what we really need is decision analytics and data science. That is, we are concerned with "real" decision making, although there are various opinions about what real really means.

The Decision Analytics and Data Science department of BISE focuses on quantitative methods, including statistical and mathematical modeling, data mining, optimization, and various algorithmic approaches to support management decision making. Topics include, but are not limited to computational logistics, network management, scheduling, revenue management, analytical customer relationship management, and recommender systems. What we probably do not need are questionnaire-based methods that optimize parameter settings using three or four expert interviews. That seems real, but not "real" enough.

Until recently, the department was called Computational Methods and Decision Support Systems. That gave it a pretty much perfect branding over many years, but left out 
important developments of the last decade. The relabeling addresses the growing role of data-centric approaches and the tighter integration/amalgamation of data, models, and algorithms. The department's scope thus forms an interdisciplinary link between computer science, statistics and data science, applied operations research, and artificial intelligence enabling innovative business applications and management decision making.

In this short paper, we aim to provide an entry point into the past, present and future of the department. On an informal basis, we would claim that now the technology is available, the data is available; we just have to put our solutions into running systems ["no systems, no impact" (Nievergelt 1994)].

\subsection{History of Decision Analytics and Data Science}

It was a long time ago that the idea came along to use models and algorithms for better decision making in complex situations. One well-known example of such early formalization is the traveling salesman problem (TSP), mentioned 1832 in a handbook for traveling salesmen as "Das Handelsreisendenproblem" and including examples for tours through Germany and Switzerland (Voigt 1832; cited by Domschke and Scholl 2010). Like for many other innovations in history, significant impulses for development of computational decision support methods have come from military applications. Even the origin of the name of the entire discipline "Operations Research" comes from the field of military operations. Linear Programming theory, established in the 1940s, has found numerous applications after the development of the simplex method by George B. Danzig in 1947. In 1975, the Nobel Prize in economics was awarded to Tjalling Koopmans and Leonid Kantorovich for the theory of optimal resource allocation.

Starting in the 1970s, the development of models and algorithms for real-life applications took its course beginning with transportation as a huge application area with some relatively easily solvable problems (or sub-problems), such as the Transportation Problem, Assignment, Minimal Cost Flow, Max Flow, or the Shortest Path Problem. With the rise of the computer era and the development of IT systems, the stronger computational power allowed for efficient implementations of planning and scheduling systems in real-world production and supply chain management. The planning systems evolved from standalone ITapplications to integrated enterprise systems enabling complex business applications, causing more impact, and inducing further challenges for research, like huge problem instances with billions of decision variables, dynamic decision processes like, e.g., operations control, and uncertain problem parameters. For such hard optimization problems, heuristics, metaheuristics, and recently math- heuristics (cf. Caserta and Voß 2014; Fink and Voß 2003; Maniezzo et al. 2009) have played an important role besides exact mathematical methods, allowing to find sufficiently good solutions in acceptable computational time.

\subsection{Decision Analytics and Data Science Today}

In the last years, the BISE-Department Decision Analytics and Data Science has focused on the engineering of information systems that enable model-based decision-making in many application areas. Most of the publications deal with approaches addressing decision support in production, transportation, and supply chains (Mönch 2006). In their research note Fink et al. (2014) proposed a research agenda for model-based decision support in manufacturing and service networks, addressing the need for interdisciplinary collaboration of business and information systems engineering researchers with scientists from management science, computer science, and operations research. Following this interdisciplinary idea, the department publishes papers dealing with decision support in uncertain and dynamic environments by connecting classical optimization systems with simulation and predictive analytics, in this way efficiently determining robust solutions in uncertain environments.

\subsection{Future of Decision Analytics and Data Science}

Future research in decision analytics and data science will move along the lines of some of the new challenges for complex business analytics arising in the era of data. Researchers and practitioners define more and more dimensions of big data, including the famous "four dimensions of Big Data" volume, velocity, variety and the in the meanwhile increasingly significant so-called veracity - addressing the trustfulness and correctness of data. Recently, further dimensions have been discussed and added. Future BISE Special Issues in our department take into account the arising challenges for data science and decision analytics.

In 2019, the focus of the department will be on "Data Analytics and Optimization for Decision Support". A special issue on this subject will present the latest advances and developments of methods, techniques, systems and tools dedicated to that relationship. The pervasive applications of the new generation of information technologies generate a massive amount of data, which makes "datadriven optimization" a new effective method for industrial optimization replacing the traditional operations research workflow of "Modeling-Algorithm-Analysis". Following these developments, this special issue will address the key question of how optimization techniques might support modern data analytics. 
Another special issue is planned for 2020, focusing on High Performance Business Computing, which includes the application of models, methodologies, tools and technologies of High Performance Computing to business problems. High Performance Computing has already found entrance into a variety of scientific disciplines, including meteorology, engineering, biosciences, physics, chemistry and mathematics. This special issue will address the need of modern business computing for high computing power and capability to deal with huge volumes of data, which includes the potentials of real-time decision making, solving computationally hard optimization problems, and analyzing the large volumes of data acquired from sensors, mobile phones, and social networks. We expect new approaches and quantitative and computational methods with a particular interest in parallel or distributed algorithms for optimization problems, data analysis and machine learning algorithms for business analytics.

A more long-term vision for our department and information systems research in general is the following. We have meetings with managers who explain their problems while we have our mobile phone on the desk. With a few indications, utilizing human computer interfaces with automatic speech recognition, we shall be able to put together a model for solving the problem, use some algorithmic approaches lying in the cloud and quickly develop a prototype for solving the problem. This prototype, even in the year 2033, when BISE turns 75, will perform some optimization but not be able to necessarily find an optimal solution in all cases. Parameterization, though, will be autocatalytic. Rather than promising too much, we should strive to get knowledge spread to the real world by adoption of research results in industry. The department will play an important role in achieving this. And, last but not least, when doing this we have to listen to the real world. We should not make their problems fit for our methods but adapt our methods to their problems (Voß 2014).

Prof. Dr. Natalia Kliewer Freie Universität Berlin Prof. Dr. Stefan Voß University of Hamburg

\section{Economics of Information Systems: Past, Present, and Future}

\subsection{Introduction}

Information technology (IT) has transformed information creation and availability and changed business practices in a wide range of industries and also the society. Because of this transformation, a number of facets related to information-based products and industries and the use of information in business and society are sufficiently unique to warrant new research that could extend economic theory.

The Economics of Information Systems department deals with the economic impact of IT on business and the society. The topics considered in this department include, but are not limited to economic models of the digital economy, electronic market design, digital goods, social networks, and social media. The department also publishes studies that explain the behavior of users or customers, as well as articles that aim at understanding business models and industry transformation. The department thus builds upon a research tradition that started to thrive in the 1990s.

\subsection{History of Economics of Information Systems}

In the early 1990s there were two separate streams of IS research. The most prevalent stream in the US had organizational science and psychology as reference disciplines and shaped leading journals such as MIS Quarterly and Journal of Management Information Systems with articles that explained human behavior in the context of information technology use in the individual and organizational setting. The second stream had computer science and operations research as reference disciplines and mainly conducted what we nowadays call - design science research. The Business Information Systems \& Engineering community had a strong impact on increasing the momentum of this second research stream worldwide. At that point, viz. the early 1990s, information systems research thus mainly focused on understanding the interaction of end users with technology and organizations from a psychological and technological perspective, and focused less on the economic implications of their behavior (Bapna et al. 2004). This duality started to disperse as more and more research began to focus on economic outcomes and used state-of-the-art economic modeling and applied econometric or analytical approaches in the style of micro- and macroeconomic studies. Early works by Erik Brynjolfsson, Eric Clemons, Lorin Hitt, Chris F. Kemerer, Haim Mendelson and Andrew B. Whinston and many others constitute the beginning of information systems research that had economics as the reference discipline (e.g., Hitt and Brynjolfsson 1996; Ba et al. 2001; Clemons et al. 2002).

Researchers in this area established workshops such as the Workshop on Information Systems and Economics (WISE) which became more and more important over the years. The first workshop in 1989 had only 22 presenters and 32 attendants. Today, WISE brings together an audience of more than 300 who participate in several parallel tracks of paper presentations.

Business Information Systems \& Engineering accounted for this development with a new department called 
"Economics of Information Systems" in 2014, and Detlef Schoder und Rolf Wigand served as the department editor.

\subsection{Economics of Information Systems Today}

Today the importance of economics of IS research is beyond controversy. Many scholars who were part of the early WISE community became senior editorial board members of leading IS journals. Policy makers recognize researchers who work at the intersection of IT and economics as advisers. Leading media often cite research from this domain (e.g., Vosoughi et al. 2018).

It has also become evident that there is a large overlap of research in the area of information systems and economics and other business disciplines that gradually turn their attention to the effect of information technology on business outcomes. It is thus not surprising that nowadays research from the IS and economics field is also publishable in some of the best economics, finance, and marketing outlets. Similarly, we observe researchers from related disciplines such as economics and marketing recognizing IS journals as suitable outlets for their research.

This development potentially obliterates the boundaries between different management disciplines, especially as IT increasingly constitutes an important enabler of all business functions. Recognizing the likely prominence of technology in the future world, IS scholars, who know how technology is designed, implemented, and used in the society, were quick to work on new and important topics way before other disciplines jumped on the bandwagon. Exemplary for this leadership is the special issue on "The Interplay Between Digital and Social Networks" in Information Systems Research, which issued its Call for Papers in 2006 and was considerably earlier than the beginning of the hype on social media and user generated content.

Moreover, research in Information Systems and Economics often bears strong relevance to related disciplines. In fact, with due consideration of technology influence, it can inform or even extend the theory and knowledge in these other disciplines. For example, IS research on crowd contribution has helped economists gain better understanding and perspectives on the incentives of people to make free contributions to open communities such as Wikipedia. Research on the economics of privacy and security in the digital world has extended the knowledge of these phenomena and provided new insights into how the stakeholders interact with each other under the influence of new technologies (e.g., Hui et al. 2007).

\subsection{Future of Economics of Information Systems}

The development of technology has given rise to many possibilities to conduct empirical studies and field/randomized experiments (e.g., Hinz et al. 2015). As a result, Economics of IS researchers have many great opportunities to test new phenomena and develop new or extend existing theories that they could not test previously. These opportunities have led many scholars to focus on the research setting but not on the underlying theory. From our point of view, it is necessary for Econ of IS scholars to construct a solid theoretical foundation and build a research tradition that can inform future work. Otherwise, we will not be able to synthesize and exemplify the knowledge cultivated from these novel empirical settings.

Bringing theory and the "big picture" into focus besides the sophisticated modeling that researchers from the economics of IS usually apply - will also help expand the influence of this community. Recent developments, including a potential regulation of Facebook, changes in the data protection law in Europe, or the potential impact of new technologies such as distributed ledgers, show that policy makers as well as managers can benefit from an informed guidance by scholars from IS and Economics.

We also believe that a synthesis of the two relatively disjoint research streams of IS and Economics and design science could yield new innovative systems and interesting insights that one stream alone cannot deliver.

We, as editors of the Economics of Information Systems department, are therefore looking forward to reading more interesting and stimulating submissions from this community.

Prof. Dr. Oliver Hinz

Goethe University Frankfurt

Prof. Dr. Kai-Lung Hui

Hong Kong University of Science and Technology

\section{Enterprise Modeling and Enterprise Systems: Past, Present, Future}

\subsection{Introduction}

Majority of business environments of today involve the cooperation of different organizations, rapidly changing business tasks and underlying technologies, as well as demanding competitive settings. Organizations therefore need the capability to respond quickly and efficiently to these challenges, and even to leverage them to competitive advantage. Enterprise Modeling (EM) is widely recognized as a catalyst for the development of IT solutions capable of following the business of today. By articulation and analysis of the strategic intentions, requirements and tasks of an organization, EM facilitates models of a future state, which explicate relevant structures, elements and their relationships, including both business and technology perspectives. The EM notion closely relates to Enterprise Architecture (EA), which applies various architecture principles through well-defined model- 
based frameworks for guiding organizations towards business and technology changes necessary to execute their strategies. Quality attributes such as agility, sensitivity, resilience, adaptability, and interoperability are further emerging to improve the efficiency of today's enterprise models. It is therefore necessary to develop methods to make it possible to take advantage of enterprise models in specific quality directions in order to create planned business value. When linked with the enterprise models, the underlying enterprise information system implements an integrated technology platform amalgamating different software applications. Its aim is to ensure that the processes, functionality and data of, for instance, resource planning, customer relationship management, supply chain management and other activities, can be integrated, shared and coordinated among the relevant units in the organization.

\subsection{History of Enterprise Modeling and Enterprise Systems}

For the purpose of business and IT alignment, systems were in the past modeled with different scopes, where one basic classification categorized functional modeling, systems architecture, business process modeling and enterprise modeling. As it can be seen in Fig. 1, the first modeling approaches emerged in late 1950s and early 1960s - Functional Block Diagrams (FFBD) and Structured Analysis and Design Technique (SADT) were oriented to express the functional view of business and systems, input and output data, as well as functional dependencies, horizontal and hierarchical. The first methods dealing conceptually with modeling of information (data) in addition to the functions emerged in the 1970s Integration DEFinition (IDEF) modeling and Entity-Relationship (ER) (Chen 1976). In the 1980s IBM introduced Business Systems Planning (BSP) as a method for analyzing, defining and designing the information architecture of organizations. Some year later, the term Enterprise Architecture was introduced for defining, interrelating and managing organizational data, functions, software applications and hardware resources (Zachman 1987).

During the 1990s, Fraunhofer Institute developed the Integrated Enterprise Modeling (IEM) method for reengineering business processes in which different aspects such as functions and data were described in one model. Business Process Modeling was proposed at a similar time as the activity of representing processes of an enterprise, so that the current ("as is") process may be analyzed and improved in future ("to be") to improve process efficiency and quality. At the time, ES started to emerge for the integrated management of core business processes, such as enterprise resource planning (Winter 2003).

The beginning of the 2000s was characterized by the appearance of Service-Oriented Architecture (SOA), the paradigm for creating EA that holds on to the notion of the service as the principal concept for modeling stand-alone units of functionality available via a defined interface. Additionally, Model-Driven engineering (MDE) has taken
Fig. 1 A historical perspective of enterprise modeling and ES

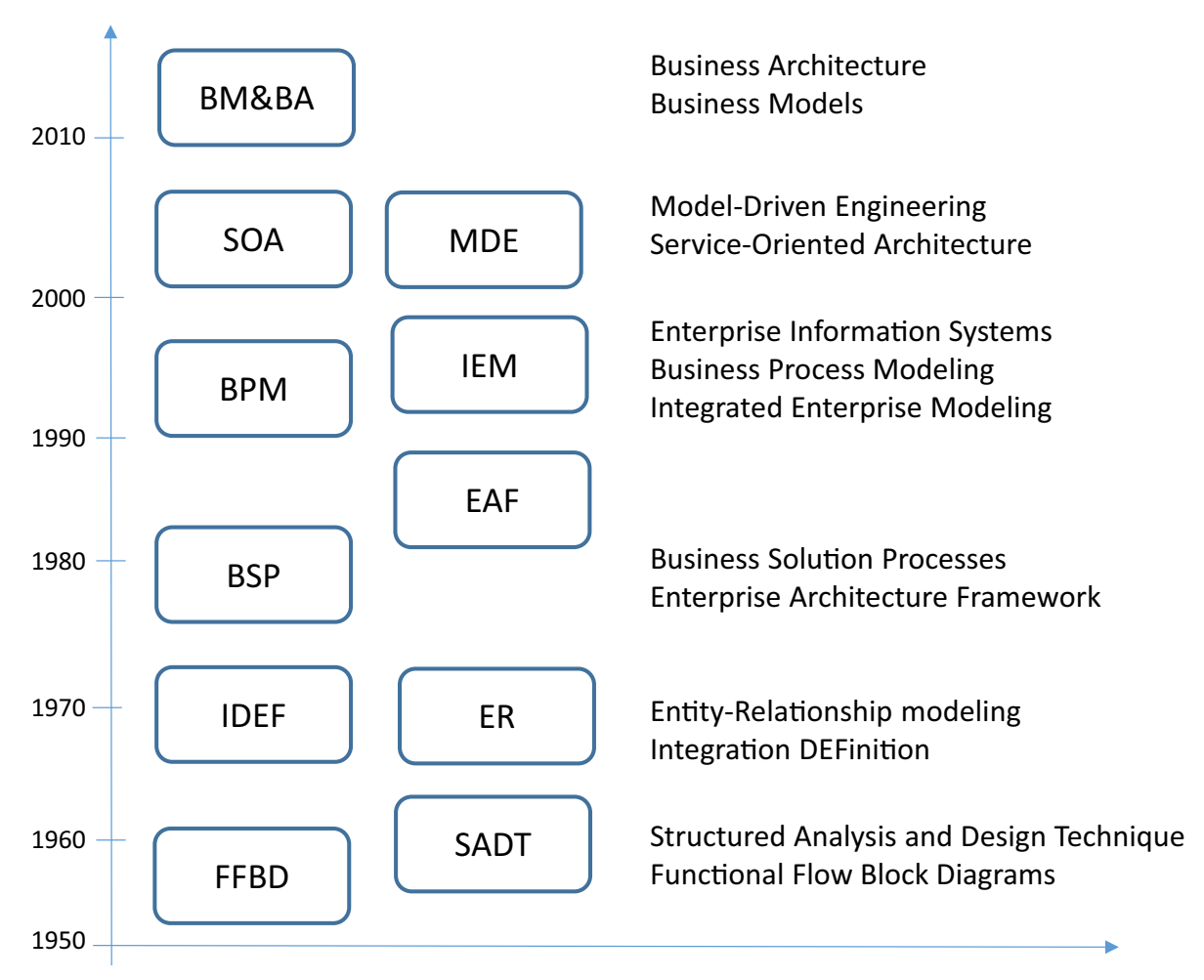


the focus on creating conceptual domain models, related to a specific application domain for providing abstract representations of the knowledge and activities that govern the domain. Lately, Business Models have been proposed for analysis and design of the operations of an enterprise with a focus on the creation and exchange of value, as well as Business Architecture Business architecture aiming to, as an enterprise blueprint, provide a common understanding of an organization, to align strategic objectives with tactical implementations.

As for the roots of EM in our journal, after the Business \& Information Systems Engineering (BISE; German: Wirtschaftsinformatik) community decided to decentralize their community journal and create five departments in 2010, the Enterprise Modeling and Enterprise Systems Department was established, with Prof. Robert Winter (University of St. Gallen, Switzerland) and Prof. Dimitris Karagiannis (University of Vienna, Austria) as founding chairs. After serving not only as department co-chair, but also as vice Editor-in-chief of BISE, Prof. Winter decided to hand over to Prof. Jelena Zdravkovic (University of Stockholm, Sweden) in 2016.

\subsection{EM and ES Today}

The EM and ES department welcomes novel research contributions to as well as surveys of the models and the method-based development and evolution for enterprisewide IS from a conceptual business perspective.

Currently, the topics of interest include advances in domain specific modeling and ES such as for utilities, healthcare, or commerce, enterprise architecture management, business models, as well as enterprise transformation management. Empirical studies considered in the articles reflect to a similar extent industrial and public sectors' cases.

Because the department periodically organizes special issues following some well-established conferences in Business Informatics, Enterprise Modeling and IS, some more specific topics emerge, such as: business modeling for networked and capability-driven organizations, enterprise modeling and requirements for changing business contexts, transformation of enterprise models for improved use from service perspectives (Zdravkovic et al. 2015). Some recent contributions also relate to data-driven EM, concerning the standardization and compliance of enterprise data models, as well as the integration and quality of the data external to organizations into enterprise modeling - from crowdsources or from big data in general.

\subsection{Future of EM and ES}

Bearing in mind the business of today, for the years to come it seems obvious is to expect that the pace of change will continue to increase, due to the need for coping with more complex business problems and supporting IT components of increased diversity, dynamics and size. Thus, in a few years from now, today's high concerns related to connectivity, integration and management of IoT with EM, big-data consolidation, and basic business intelligence, will fade away. We also expect an increasing multi-modality of management to create needs for adapting EM and ES classical process-oriented "back stage" harmonization is increasingly accompanied by highly volatile "front stage" support (digital interactions) and recently by wide-scale data-driven exploration.

To survive and make advances, business organizations will need to be proactive for changes, internally and externally tightly connected in digital terms to speed up information flows, responsive to dynamically changing situations, scalable to changing customer needs, globally integrated, as well as modular and extensible to assemble and augment business capabilities on demand. Therefore, one of the main concerns of EM and ES will be to master continuous transformation for business ecosystems spanning increasingly agile organizations and increasingly networked organizations.

This means that both organizations and their information systems will need to be prepared for possible later changes during the design phase. This will require structural enterprise models with highly refined horizontal and vertical relationships enabling to accurately plan, analyze, simulate and implement new business states, as well as to reshape the structure and the size of the architectures at the pace in which the business ecosystem evolve. To be able to efficiently support such requirements, the EM and EA models will in the future rely on a variety of structural algorithms, which will increase task automation. By such augmented intelligence, the models will be able to streamline best future actions and business strategies, while the underlying ES will be configurable to deliver intended services regardless of the size of the change of course.

Prof. Dr. Dimitris Karagiannis University of Vienna Prof. Dr. Jelena Zdravkovic Stockholm University Prof. Dr. Robert Winter University of St. Gallen 


\section{Business Information Systems and Computer Science in the Time of Digitalization}

\subsection{Introduction}

The research questions addressed in papers submitted to the BISE Department "Information Systems Engineering and Technology" (department editors: Matthias Jarke and Matti Rossi) have once again changed dramatically since the 50th anniversary of the journal.

In 2006, the German government dedicated its Science Year for the first time to the field of Informatics. In "Informatikjahr 2006", our emphasis in over 400 public events was on alerting politics, business, and society to the increasing importance of Computer Science and Information Systems. At the end of the year, we had the feeling that some progress had been made, but public awareness of the importance of IT was still far from where we wanted it to be.

Only 8 years later, the situation had completely changed. The German government organized the "Digitalization Year 2014". Especially driven by the instant and enormous success of the Smartphone introduction by Apple in 2007, there was little doubt left that digitalization was one of the megatrends and societal challenges for Europe in the twentyfirst century. Four years later, the digital competition among the US, China, and Europe dominates political discussions about technological strategies and the future of labor due to the new wave of automation initiated by the Internet of Things and the revived attention to Artificial Intelligence.

In this competition, Europe and Germany have pursued quite a different strategy than the US, with strong implications for the role of Computer Science and Business Informatics research and their interrelationships. In this short paper, I shall briefly sketch these developments, resulting in the observation that, in cooperation with further disciplines, CS and IS research have strengthened their joint efforts to take on the digitalization challenges and thus also gained more visibility in the international community. The paper ends with pointing out some areas where major technological breakthroughs create significant new cross-disciplinary research opportunities.

\subsection{Digital Disruption Versus Digitalization}

Digital platforms have had disruptive effects for broad sectors of the economy. Silicon Valley analysts such as Thomas Friedman (2005) or Brian Arthur (2009) observed that these platforms follow an evolutionary pattern by recombining technological components bottom-up, starting with the Information Highways advanced by the Clinton/ Gore administration in 1992, made widely usable by the
HTTP standards of the World Wide Web since the mid1990s, and continuing from generic services and tools such as search engines to sales platforms such as Alibaba, Amazon, or Uber. Economically, such platforms are often organized as market intermediaries in business-to-consumer settings, or as three-sided markets where the income of the platform owner stems from advertising associated with free services (Gawer 2014).

In the seemingly exponential growth of such platforms, two factors come together: the ever-increasing computing and communication power from parallel hardware settings and algorithms even beyond the end of the original Moore's law for single processors, but also the network effects that increase the value of communication networks quadratically with the number of participating nodes. Taken together, this can lead to worldwide monopolies or oligopolies if the home markets of platform owners are large enough to reach initial network sizes of hundreds of millions of nodes. The situation vividly reminds of colonial developments where shipping companies and certain wellpositioned ports managed to obtain huge trade profits through the bundling of sea traffic, or the early 1900s with Rockefeller's forced transition to oil-hungry car traffic through disruption of train tracks.

In the Informatikjahr 2006, the German and subsequently other European governments and industries began to recognize the disruptive potential that this gradual bottom-up IT infrastructure domination could pose to areas where Europe had traditionally strong market positions. The "Hightech Strategy" introduced by Chancellor Angela Merkel tried to counter digital disruption by a verticalization approach to digitalization in which major industrial domains of traditional European strengths such as the car industry, machine industry, logistics, or medical technology, were to devise domain-specific platform strategies. The most famous example of such a verticalization strategy, Industry 4.0, was introduced as an official term at the Hannover Fair 2011 and brought together engineering, computer science, and business in the industrial sector. Thus, the traditional European leadership in complex Embedded Systems Engineering could be brought into play, just when the parallel progress in sensor development and fast mobile communication technology enabled the explosive growth of the so-called Internet of Things and Services (in the US also called Industrial Internet) and thus a confluence towards huge Cyber-Physical Systems. Industry 4.0 has since become a world-wide trend especially in China which is exploiting its size to attempt to pursue both ways simultaneously - bottom-up generic tools such as Alibaba, Tencent, or Baidu, and verticalization in Industry 4.0.

As already observed in the 50th BISE anniversary issue (Jarke 2009), the strategic move towards digitalization of 
vertical industries - limiting local generic platform efforts to copycats of international originals, or focusing on domain-specific business-to-business platforms - has had profound consequences for computer science and business informatics alike, bringing both areas closer together through the Design Science paradigm for focused domainspecific IT research in domains such as industry, healthcare, mobility, energy, and other fields.

Looking back, these initiatives had quite a positive influence on the international standing of both research areas. A Citeseer-based analysis by this author in early 2000 showed only 13 Germans among the 1.000 top-cited computer scientists worldwide, many fewer than in a lot of smaller countries. By August 2018, according to a worldwide h-index ranking (Bichler 2018b), this share has more than tripled to 45 researchers, which means the third place after the US and UK. Similarly, in Business Informatics, accepted papers from Germany achieved the second place at the flagship ICIS conference, coming from just a few regular attendees until the mid-1990s. In addition, the BISE internationalization strategy has multiplied the journal's impact factor tenfold, bringing it into the top group of international IS journals. The scientific success of the CS/ IS confluence is perhaps best highlighted by the surprising observation that an author positioned exactly at the crossroads of both fields - linking the typical IS issue of business process management to a classical theoretical computer science formalism (Petri nets) - has become the most-cited Computer Scientist in Continental Europe for the last several years. On the industrial innovation side, this fruitful symbiosis has also enabled leadership in one of the important trends for machine learning solutions according to recent Gartner analyses, namely the field of Process Mining (van der Aalst 2016).

\subsection{Some Directions for Co-Innovation Between CS and IS}

What we completely under-estimated 10 years ago, was the uptake speed of cyber-physical systems, initiated by the coinvention of a confluence technology of Internet and mobile phone (smartphone) with a completely new business model (Apple Store) taking optimal advantage of the network effects. This kind of co-innovation combined with flexibility and extensibility might increasingly replace the traditional distinction between technology push and application pull, further strengthening the case for trans-disciplinary cooperation among Information Systems, Computer Science, and domain disciplines. A recent example of such co-innovation is the intensely digitally supported development of low-cost electric vehicles at RWTH Aachen University (www.streetscooter.eu) which transferred the agile software engineering process SCRUM to car development and even factory planning (Schuh et al. 2011). This enabled for example four radical re-designs of their e.GO low-cost private car, within less than 3 years, while at the same time successfully defining a niche market not yet addressed by competitors.

At least three important technological trends can be seen as worthy candidates for such co-innovation opportunities.

Although computer graphics, vision and speech handling have been long-term research topics for electrical engineers and computer scientists, coherent scientific communities in these areas have formed rather late (Pham et al. 2011). Nevertheless, by 2018, their lead conferences have reached the highest impact rates within all computing (Bichler 2018b). These advances, in practice illustrated by face and speech recognition in smartphones and in smart home devices such as Amazon's Alexa, stem from a confluence of improved sensor technologies with breakthroughs in the numerical stability that, after 30 years of fundamental research, made the old idea of multi-layered neural networks (Rumelhart et al. 1986) practicable and thus enabled what is now called "deep, learning". Besides new levels of vision and speech capabilities, deep learning has shown its advantages in many domains where massive amounts of training data but relatively little prior theoretical understanding is available. However, for many other digitalization tasks, e.g., in engineering, training data are limited and many valuable theories are available, from material science all the way to process models. This creates a research need for hybrid solutions between machine learning, application of known laws in fast mathematical models, and real-time data mining.

Not only here, "data science" is at the core. The "big data analytics" of a decade ago are nowadays capturing a much broader variety of data, and require real-time data stream processing capabilities where data are analyzed on the fly. In engineering control, communication latency is re-emerging as an important bottleneck, and the vision of global cloud solutions has to be expanded with more flexible edge-fog computing architectures where computation load and communication load must be traded off dynamically. The next round of such trade-offs is forthcoming with the emerging $5 \mathrm{G}$ standards.

However, data science also raises important societal and economic challenges. One much-debated aspect remains personal privacy with its traditional emphasis on data sparsity ("need to know principle") which sharply contrasts with the global data capturing used by big players in industry and public sector for advertising and security monitoring. Much less addressed is the related issue many small and medium enterprises, even large user organizations, e.g., in medicine or manufacturing, are facing concerning the data sovereignty over their own data. While, 
according to the European privacy guideline, individuals are considered objects of law-enforced protection, organizations must be empowered - legally and technically - to decide in a sovereign manner how they can share their data in a controlled manner. Simplistically, we must study how a contract of usage can be attached to all exchanged data. An architecture and governance framework with trusted connectors and security policies as well as heterogeneous modeling tools for data sovereignty is being developed by the Fraunhofer-led International Data Space initiative (Otto et al. 2018; Jarke 2017), and evaluated in use cases in sectors like production and logistics, medical information management, material sciences, and other fields.

Last not least, to accomplish the vision of coordinated and human-centric environments with autonomous intelligent agents (robots, autonomous cars, and the like), the "Digital Twin" has become a central concept. Digital Twins (e.g., Uhlemann et al. 2017) aim to be full-scale virtual duplicates of their accompanied real distributed system (e.g., a factory floor, a complex machine sequence, or a logistic chain), living in parallel to, and interacting with the real system. While this is partially already working quite well at a coarse-granular level with relatively low speed, current simulation technologies (e.g., Finite Element Simulation) are far too slow for real-time support. Moreover, as experience from 50 years of data management shows, the growth of data produced by these simulations and the related sensor systems of the real as well as virtual system, will always outpace our abilities to process these full data sets. We therefore claim that real-time control of complex technical systems will have to rely on carefully crafted collections of "Digital Shadows" which innovatively combine strongly simplified mathematical models from domain theories with feedback from real-time data and experience-based machine learning. Work on process mining (van der Aalst 2016) and strategic requirements modeling (Jarke et al. 2011) indicates that this is a useful hypothesis not just at the technical level, but equally extends to the lifecycle-wide business and economic platform analysis.

Prof. Dr. Matthias Jarke RWTH Aachen University and Fraunhofer FIT

\section{IS Foundations and Research Methods: Past, Present, Future}

\subsection{Introduction}

The department IS Foundations and Research Methods provides a forum for the presentation and discussion of contributions on methodological, epistemological and ontological foundations of information systems research. It also welcomes papers on ethical issues, the evaluation of research results as well as critical analyses of the institutional context of information systems research. With respect to the number of submissions and published articles, the department is by far the smallest of the journal. Most submitted papers so far focused on research methods. The majority of those was related to design science. The relatively low number of submissions on foundational aspects corresponds with experiences made with respective tracks at major conferences. However, that is not an indication of a lack of relevance or interest. There is no doubt that research methods are of pivotal relevance. They are at the core of scientific investigations and they are an essential characteristic of our identity as academics. Even though behaviorist methods are widely used and may be regarded as a "standard" by many, the methodological challenges which research on information systems is confronted with are far from overcome. This is for various reasons. First, the epistemological and ontological assumptions underlying a research method can hardly be generalized for any kind of research in our field. That creates the need to tailor research methods to specific characteristics of research projects. Second, with respect to promoting scientific progress, methods are ambivalent. On the one hand, they provide us with guidance and confidence. They foster academic discourse by providing a common framework of reference. They also promote the comparability of research results, since they recommend a common structure for conducting and documenting research. On the other hand, methods may also give us a false sense of confidence and limit our imagination. Therefore, it is probably more desirable to strive for independence from particular methods, or even to be "against method" (Feyerabend 1993), rather than aiming at mastering one particular method. However, independence from particular methods can be achieved only if various methods and their underlying presuppositions have been thoroughly studied. Third, the philosophical and terminological foundations of research methods are all but mature. The lack of final answers is not discouraging, but rather an invitation to an inspiring, never ending debate.

\subsection{History of IS Foundations and Research Methods}

60 years ago, at the dawn of our discipline, research methods were not an explicit item on the agenda of the pioneers. Nevertheless, the latter had to deal with foundational aspects in a literal sense. How should the study of business information systems be positioned between business and administration and computer science? What were primary research goals? How could the transfer between academia and practice be organized? In addition, the early 
representatives of our field had to struggle with university environments that were not always friendly or even "hostile" (Weber 1997, p. 13). That created the need to gain legitimation. Here, "Wirtschaftsinformatik" took a different approach than "Information Systems" in the US. While our colleagues in the US focused on adopting research methods from established fields, especially from the natural sciences, the founders of "Wirtschaftsinformatik" gained recognition through the collaboration with industry and impressive amounts of external funds (Frank et al. 2008). Since this model was relatively successful for a few decades, there was not much need to develop or explicitly use research methods. Nevertheless, there was a small group of researchers who was interested in methodological questions. They were inspired by the positivism dispute in philosophy and sociology and established a conference series, starting in 1997 (Becker et al. 1999). Even though most of the participants were enthusiastic about the topic, they had moderate impact on the mainstream only. The common appreciation of research methods changed at the beginning of this century, when strong industry relations were no longer sufficient to gain reputation. Instead, the quest to publish on an international scale required the explicit use of research methods. At the beginning, only very few embraced the behaviorist methods that dominated the international scene. Various authors warned of the adoption of behaviorist methods, both for epistemological and pragmatic reasons. In addition, there was an initiative that developed and proposed a memorandum for designoriented research as an alternative to design science (Österle et al. 2011).

\subsection{IS Foundations and Research Methods Today}

There are indications that Information Systems is in the state of "normal science" (Kuhn 1964), that is, research is usually based on the leading, behaviorist paradigm, and problems are mainly analyzed from within the paradigm. This situation may contribute to the perception that there is not much need to discuss the foundations of our discipline. However, especially in times of a seemingly mature paradigm it is important to once in a while challenge the underlying assumptions and the foundational terms our research builds on. Most methods rely on the existence of theories. However, we still lack a definition of theory that would clearly allow to discriminate between knowledge that qualifies as theory and other knowledge that does not. In 2016, the department launched a discussion of concepts of theory. 10 colleagues participated in the discussion that was documented in a joint article (Bichler et al. 2016). The discussion showed a remarkable diversity of theory concepts. It ranged from formal conceptions of theory over relaxed notions of theory, relativist views on theory to the representation of theories as conceptual models. In any case, the concept of theory will usually relate to truth as the ultimate evaluation criterion. However, there are various concepts of truth (Künne 2003), but no consensus about a specific concept or even about the utility of the idea of truth in academia.

There are two main streams of submissions the department received during the last years. Various authors aim at refinements or adaptations of design science, which probably reflects the relevance of construction-oriented research especially in certain parts of Europe. Others propose the integration of behaviorist and hermeneutic aspects into methods that enable a larger degree of flexibility.

\subsection{Future of IS Foundations and Research Methods}

There are good reasons why work on foundational aspects of our field will be of great relevance in the future. The digital transformation that we are currently witnessing creates impressive opportunities but also obvious threats. Since our research aims at the center of this transformation, one may argue that we have a specific responsibility to support society to benefit from change instead of suffering from it. On the one hand, that would imply to account for ethical aspects of digitization (Rogerson et al. 2017). On the other hand, it would suggest to reflect upon research methods and cognition in general. Current methods are predominantly focused on the analysis and explanation of the past. In an ever changing world, such an approach bears the risk to produce pictures of a moving target without providing a substantial orientation for change. That suggests that methods should develop and investigate images of the future. They could focus on uncovering subtle political effects of information systems and foster "democratizing potentialities of technology" (Chiasson et al. 2018), or they could aim at developing grounded scenarios of possible future worlds that serve those who create the future as useful orientation (Frank 2017) - and thus supplement truth with grounded hope as a pivotal orientation of our work (Rorty 1999). Furthermore, the ever growing digitization of the world enables automated research through inductive reasoning that is based on massive amounts of up-to-date data. One does not have to agree with Pentland who already foresees the end of the social sciences (Pentland 2014). But there is no doubt that many questions addressed in today's research projects can be targeted by machines in the future. This development recommends a critical analysis of the limits of inductive reasoning - and of how future methods can take advantage of machines to enhance human cognition. In addition, the digital transformation is challenging the foundations of our profession as academics, both in teaching and research. It enables new ways of representing and exchanging research results, more efficient approaches 
to judge academic excellence, and has the potential to shatter what we took for granted in the past. Therefore, it seems appropriate to follow Rowe who does not only suggest that IS researchers emphasize a critical perspective on the (mis-)use of information technology, but that we should also account for the vast volume of discourses in philosophy that provide useful clarifications, and - at the same time are suited to free us from inadequate certainty (Rowe 2018). At the same time, it seems reasonable to reflect upon misconceptions, misleading incentives and rituals in our practice as academics to contribute to an intellectual "hedonism" (Frank 2014) that promotes the university as a very special place in society.

Prof. Dr. Ulrich Frank University of Duisburg-Essen

\section{Management and Use of Information and Knowledge: Past, Present, Future}

\subsection{Introduction}

When in the 1970s computers began to enter the professional workplace, managers soon realized their potential to not just automate and support clerical work, but to transform business, industries and society in large (Somogyi and Galliers 1987). The arrival of the airline reservation systems Apollo and Sabre in the $80 \mathrm{~s}$ is a case in point. These systems enabled their originators, American Airlines and United Airlines, to outperform their fiercest competitors and revolutionized the entire travel industry (Applegate et al. 1996). Since then, it has been widely accepted that information technology (IT) and the information and knowledge associated with IT - are assets that organizations need to manage efficiently and effectively in order to stay competitive. In fact, information technology has been framed as an "intellectual technology" that "as opposed to an industrial technology, (...) like a drill press or steam engine, (...) has functionalities that are not fixed at the outset, but can be innovated endlessly, depending on its interactions with the intellect of human beings who implement and use it" (Lee 1999, p. 8). Accordingly, organizations face the challenge of managing (i.e., planning, organizing, controlling and governing) the ongoing process of investing into IT assets, converting them into information systems (IS) that process and generate information and knowledge, and using the resulting IS so that they result in improved organizational performance (Fig. 2; Heinrich 1995; Krcmar 1997). Exemplified areas of research that fall under the management and use of information and knowledge are hence IT investment decision-making, IT strategic planning,
IT-business alignment, IT outsourcing, IT controlling, and IT adoption, diffusion and use.

\subsection{History of Management and Use of Information and Knowledge}

While research on the management and use of information and knowledge dates back to the early $70 \mathrm{~s}$, it gained momentum in the late $80 \mathrm{~s}$ and early $90 \mathrm{~s}$.

Planning. One of the early streams of research has dealt with the strategic impact of IT, i.e., the notion of IT as a strategic weapon. Inspired by Michael Porter's (1980) seminal work, scholars began to analyze the strategic and transformational role of IT within and across organizations (Mertens and Plattflaut 1986; Porter and Millar 1985). The role of IT as an enabler of change became prevalent as illustrated by various illuminating industry examples, such as the virtualization, digitalization and industrialization of banking (e.g., König 2002; Roemer and Buhl 1996). Moreover, with the increasing interest in the strategic role of IS, research began to examine the issues of strategic fit and business-IT-alignment (e.g., Beimborn et al. 2006; Roithmayr and Wendner 1992). In parallel, research interest grew on how to make economically feasible ITinvestment decisions (e.g., Schumann 1993). For example, studies emerged that sought to develop tools for estimating the costs of IT investments and projects, including approaches of IT-portfolio management. Finally, metastudies began to take stock of the empirical evidence for the economic value of IT investments (e.g., Potthof 1998). While this pool of studies has mostly been concerned with IS planning, studies on IT organizing, controlling, and governing quickly followed suit, accompanied with studies that focused on the user, i.e., use of IS.

Controlling IT-controlling studies were concerned with developing instruments for assessing the long-term and ongoing effects and associated costs of IT-investments, e.g., through balanced scorecards. In addition, empirical evidence of IT-controlling activities was assessed (Spitta 1998). The topic of IT-controlling then widened out to include related topics of IT control and IT compliance.

Organizing In terms of IT-organizing, a strong focus was set on understanding IT-outsourcing decisions and managing IT outsourcing contracts (e.g., Dibbern and Heinzl 2001; Lacity and Willcocks 2003; Szyperski et al. 1993). This stream of research also lead to an increasing interest in studying outsourcing from the viewpoint of ITproviders. This shift in perspective continued later with the emerging research streams on cloud computing services and platform ecosystems (Benlian et al. 2009; Weinhardt et al. 2009). Notably, this shift in perceptive also 
Manage:

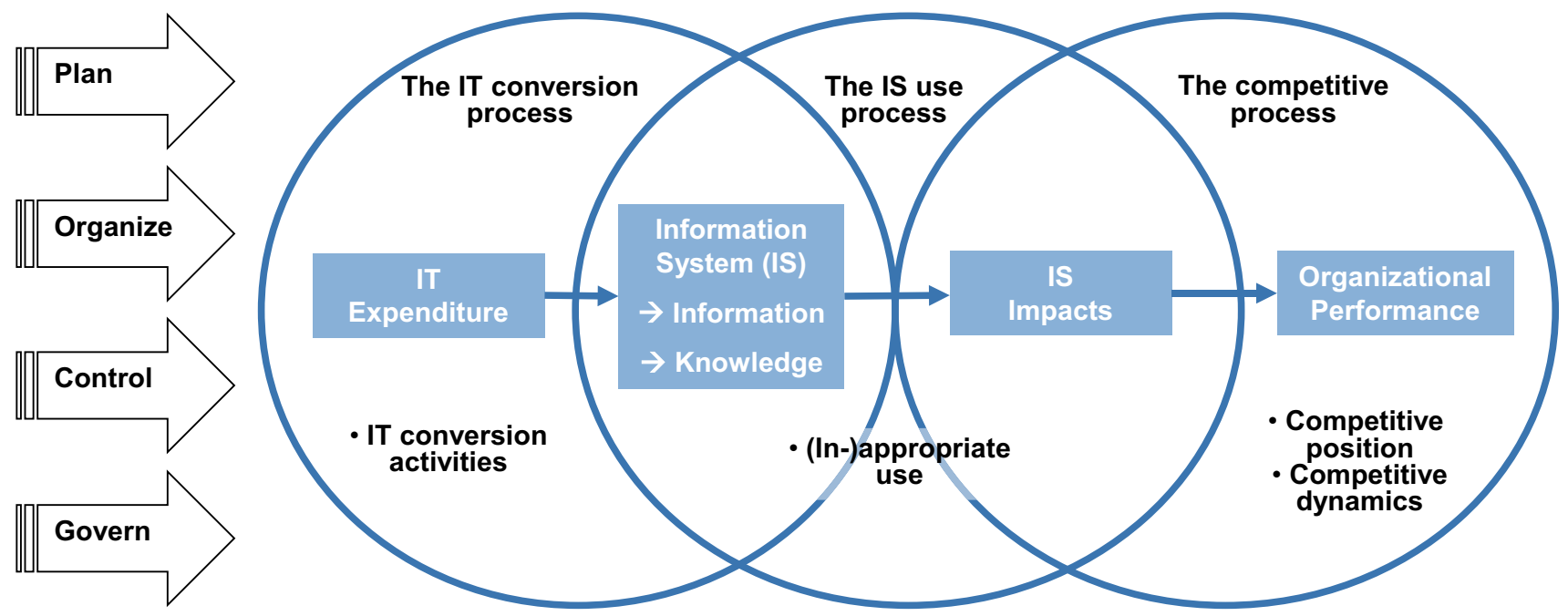

Fig. 2 Overview of management and use of information and knowledge. (Adapted from Soh and Markus 1995, p. 37)

revitalized research on planning and controlling from the perspective of IT service providers and IT product developers.

Governing The topic of governing (i.e., governance) is concerned with the distribution of IT decision rights including the issue of centralization versus decentralization within organizations (Köbler et al. 2010) - an issue that has also been examined in the context of mergers and acquisitions (Penzel 1999).

Use Notably, while research concerned with management issues, such as planning, organizing, and controlling, typically took a firm or industry level perspective, a parallel stream of research on the use of information and knowledge systems developed early on that increasingly took an individual level perspective, specifically the perspective of the user. In fact, one notable stream of research that has been established at an early stage in IS (including the predecessor of BISE, i.e. the journal "Wirtschaftsinformatik") refers to the study of computer support for cooperative work (Heinrich 1993). This stream acknowledges the ability of IS to change the way humans interact with each other in their daily work. Later on, this stream of research emerged into studies on knowledge management systems followed by recent trends towards studying the use of social media systems in organizations. This development towards putting the spotlight on the users has led to keen interest in studying the users' affective, cognitive and behavioral responses to newly introduced systems, such as emotional reactions, technostress, and privacy concerns (e.g., Krasnova et al. 2012).

\subsection{Management and Use of Information and Knowledge Today}

Concerning ongoing work currently being published and submitted to this department, it is notable that many of the basic topics concerning the management and use of information and knowledge still matter today. For example, interest in traditional themes of IS strategic alignment, IS outsourcing, IS governance, and IS investment decisions prevails, but these themes are also put into new perspective, e.g., in the light of new service-delivery models (i.e., cloud services) and the network-based economy (i.e., platform ecosystems and crowd sourcing). Moreover, interest in strategic transformation through IS has been revitalized through greater interest in managing digitalization and digital transformation. In this realm, the role of IS as an enabler of change has regained interest, e.g., by fueling innovation processes in organizations through ITenabled initiatives, such as crowdsourcing (Durward et al. 2016), or through disruptive IT-driven industry changes as evidenced by the sharing economy (Puschmann and Alt 2016). Finally, research continues to examine the (changing) role of the user in the age of digitalization.

\subsection{Future of Management and Use of Information and Knowledge}

Looking ahead, it may be assumed that the strong theoretical and empirical foundations established by prior work on the management and use of information and knowledge will remain cornerstones of future work. As IT remains a moving target that continues to change the world in 
unpredictable scope and speed, the role of strong theorizing will become ever more important.

One theme in such emergent research might center on a reconsideration of the separation of stages and respective roles in the management and use of information and knowledge. As depicted in Fig. 2, the process of IS use lies at the interface of the IT conversion process and the process of generating IT impacts. Yet these processes (i.e., circles in Fig. 2) have often been studied in isolation or as separate phases in prior research. Three exemplified trends might challenge this separation and call for a more integrated view of studying the management of the interdependent process of IT conversion, use, and impact.

The first is the increasing adoption of agile development methods in organizations, where managers, users, and developers jointly take part in the IS conversion process. This blurs the boundaries between principals and agents, e.g., between business managers and users, IT managers and developers, and users and developers. Thus, the whole notion of 'managing' might need to be rethought in the light of the integration and interaction of various IS stakeholders. Second, the increasing diffusion of the software-as-a-service (SaaS) model blurs the boundaries between IT product developers and users. While traditional providers of on-premises software had little knowledge about the actual use of their products by clients (i.e., the actual users), SaaS providers keep a direct link to the end user. In fact, SaaS providers can actually observe and track usage behavior, analyze user behavior, and react accordingly, e.g., by trying to stimulate the use of particular software features or by learning from (inappropriate or non-) usage and developing new releases. Thus the whole notion of value-oriented IT product development and IS use might need to be re-evaluated in the light of such service-oriented IT provisioning models. Third, we currently see the arrival or in fact revival of applications of artificial intelligence, i.e., self-learning systems, in organizations (van der Aalst et al. 2018; Sprenger and Mettler 2015; Willcocks and Lacity 2016). Through such AI systems, IS become smarter and hence will increasingly substitute more complex human work and decision-making. Thus, one may ask whether IS users will increasingly disappear from the landscape or whether new types of users will emerge that interact with such smart machines. Accordingly, one may re-ask the question of how "the smart machine" will affect the "future of work and power" (Zuboff 1988). The increasing adoption and diffusion of AI-based systems also creates the challenge of staying in control of such intelligent systems that become increasingly autonomous. One may further imagine how such systems influence the strategic role of IS. Will they spark a race between organizations for developing and using the most intelligent systems (i.e., robots) in order to outperform competitors? Moreover, from an organizing point of view, one may ask what the role of IT product and service providers will be in helping organizations (and users) leverage the potential of AI. Will the principle-agency problem disappear as soon as we are increasingly able to inscribe our interests into robotic systems?

When examining such emergent phenomena with their inherent complexity, it appears advisable to sit on the shoulders of giants, i.e., pre-existing theoretical and empirical knowledge that may increasingly span neighboring disciplines. Rather than ever-extending existing theories and thereby increasing complexity up to the level where the real world is modeled on a 1:1 scale, the challenge will be to scale down complexity to a manageable level - also for the readership of BISE. This will likely only be possible by either modifying and adapting (rather than extending) existing theories or by developing new theory that may be informed by prior (meta) theory as a base of reference. In any case, we wish to see papers that take up real world phenomena in the realm of the management and use of information and knowledge, carve out those aspects that are new, and generate new knowledge rather than reiterating existing knowledge. We specifically also welcome conceptual work and applied research, such as action research.

Prof. Dr. Jens Dibbern University of Bern

\section{Views on the Past, Present, and Future of BISE - Business and Information Systems Engineering}

\subsection{All Flows, Nothing Stays}

"There is nothing more constant than change." A wisdom by Heraclitus more than 2500 years old now seems more relevant and recent than ever. And change does not spare the BISE community. In 2019 Martin Bichler will pass the torch of the Editor-in-Chief into my hands and it will be carried on along this path of constant change.

Change is nothing bad and nothing to fear. Especially in our community change is one of the greatest potentials that we possess. And it may be our greatest strength. Ever since its foundation, the BISE community - despite its relatively short existence compared to other traditional sciences and disciplines, such as philosophy, psychology, or theology has researched with cutting-edge technology and shaped the way we work, live, communicate, travel, and decide. Therefore, we do not just tackle changes that happen, but to a significant extent we are eager to guide this change. It is our responsibility as a community, as researchers in one of today's fastest changing environments, to drive this change to benefit us all and to make this our strength.

But to break these rather philosophical words down: What is really changing our community right now? 


\subsection{Our Community Will be More Diverse}

Some trends can easily be seen by a quick look at the BISE statistics. Researchers publishing in BISE have and will become more international. By this we will gain more international visibility, something that we definitely should continue and promote with our joint efforts. Our reality has rapidly become more global, more international. Apps that were developed in the United States, such as, Microsoft Office or Google Search, organize our workdays in Germany. At the same time European enterprise resource planning software, such as that from SAP as a lighthouse of the German software vendors, manages business processes in Asia and everywhere in the world. Therefore, software and information systems do not only have to address local requirements. We as researchers need an international exchange on current problems, perspectives, research opportunities, and also of different cultures in order to gain a holistic understanding of the challenges and potentials - with the ultimate goal to invent, develop, and improve information systems that change the world to the better. Heterogeneity in groups is a real challenge, but it can also lead to a higher quality of results and decisions (Shachaf 2008).

Becoming more diverse and dispersed, however, increases our responsibility to stand together with all our different backgrounds and experiences. This means to exchange more of our ideas and competencies and to appreciate other approaches and research methods, other cultures, and opinions. $\mathrm{We}-$ as the BISE community and me as future Editor in Chief - can work on that with a joint effort. Hopefully, in the future we will keep on seeing this diversity of methods, backgrounds and even cultures represented in our editorial board as well as in the department structure. Careful but continuous changes there will help us to dynamically include new groups and streams of our discipline on a global level - without losing quality.

Quality in research itself on the one hand - meaning the authors' work - is one of the main assets we have. On the other hand, the effort of reviewing the papers submitted is the second one. This comprises not only our joint hard work as community with respect to quality AND time, but also the reviewing process at the organizational and managerial level - one of my main responsibilities from 2019 on - falling back on all people involved up to the lectoral work of highly experienced people of our community and at Springer.

\subsection{Our Community Will be More Participatory}

Widespread information technology has already softened many gridlocked structures (Picot and Baumann 2009). Information asymmetry was massively reduced by the internet and its widely accessible information. This also made strong hierarchical structures and unnecessary dependencies lose their importance. The society has changed towards self-determined individuals that want to participate with their opinion and knowledge. We see this motivation in the passion and effort our reviewers put into their sometimes frustrating work.

Conferences, probably most notably the CHI, try to reduce information asymmetry in their reviewing and publishing process by the introduction of rebuttals. This means, that the review process is extended by a further loop between the author and the reviewers, in which the author can respond to a preliminary version of the review before the final review is written by the reviewer. Other outlets require the authors to submit their underlying data and evaluation scripts to the reviewing process in order to reduce information asymmetry. In which way these measures really help and can be designed in a way so that they do not assail the rights and obligations of any party and/or reduce a necessary level of privacy is an open question and a matter of discussion. Which kind of feedback would authors appreciate and which information and feedback do also reviewers need in order to better assess and push forward the articles' quality? And is there a party that does not yet participate but would also be able to contribute significantly? Often a second opinion, even from a different field, may help understand a certain issue in increased depth, find possible generalizations, and narrow contributions where necessary. Our inherited interdisciplinarity can support this process. Shaping this process and increasing the potential of participation even at the level of the review process may be further discussed in future. Enabling all parties to participate in an appropriate and convenient way is also a kind of appreciation of their work and knowledge and thus follows the trends in nowadays society.

\subsection{Our Community Will be More Interdisciplinary}

Ever since the BISE community was founded it had to advocate for its mission and relevance as a new discipline in between computer sciences and business, management, and economics. Though initially smiled at from both sides, we really managed to bridge these two fields and thus create real value for research as well as for practice. Our research helped to understand how technology is perceived, used, and adopted. Nearly all companies today rely heavily on information systems and the staff developing and maintaining them.

However, this mission continues and is even growing in importance. Current research has already shown for some time that our interdisciplinarity is no longer restricted to computer science and business fields. Findings from psychology have entered consideration in software design, nudging, and decision making (e.g., Jung et al. 2018). Legal requirements regarding copyright or privacy and data security require our attention (Bélanger and Crossler 2011). 
Biology is becoming relevant for our NeuroIS research. All these changes are not only challenges. They bear high potential and responsibilities.

The BISE community can help to bridge these other fields of research and thus help to spread findings across them. It is our strength that we understand many application and research problems, upcoming technical innovations and research contributions at the same time. Hence, it is up to us to (re)combine them to new applications in other contexts. According to Gassmann et al. (2014), 90\% of all innovation regarding business models is a reconfiguration and combination of existing ideas into new contexts. For this reason we will also continue to keep a steady eye on submissions of that kind to the BISE journal to ensure and nourish fruitful interdisciplinarity and the transfer between disciplines.

\subsection{What Remains}

"We shape our tools and then our tools shape us." (John Culkin 1967) literally describes what has become reality with the entry of information technology into every section of our everyday lives. This is also true for our community. Yet we have seen that technology and related opportunities have and will make our community more diverse, participatory, and more interdisciplinary. With our research we will shape the future and finally our own lives. To shape the structure and processes of our community outlets is one way of fostering our community as a whole. I am glad that the BISE journal thanks to the last predecessors Martin Bichler and Hans Ulrich Buhl and their teams - currently is in an excellent condition to face these ongoing changes. I am looking forward to doing my best in order to continue their work by guiding the upcoming challenges conscientiously and serving our research community as Editor in Chief of BISE for the next few years.
Prof. Dr. Christof Weinhardt

Karlsruhe Institute of Technology

\section{The BISE Journal in Numbers}

Downloads

\begin{tabular}{|l|l|l|}
\hline & 2007 & 2017 \\
\hline Downloads & 12.000 & 190.179 \\
\hline Page visits on the BISE homepage & $<1000$ & 221.275 \\
\hline
\end{tabular}

Submissions

\begin{tabular}{|l|l|l|}
\hline & 2007 & 2017 \\
\hline Number of submissions & 71 & 271 \\
\hline Papers in process & 9 & $>100$ \\
\hline
\end{tabular}

Citation metrics

\begin{tabular}{|l|l|l|}
\hline & 2007 & 2017 \\
\hline 5-year impact factor & $<0.3$ & 3.586 \\
\hline Scopus CiteScore & $<0.3$ & 2.760 \\
\hline SNIP & - & 2.068 \\
\hline Google h-index & - & 29 \\
\hline
\end{tabular}

Process

\begin{tabular}{|l|l|l|}
\hline & 2007 & 2017 \\
\hline Number of days for first decision & $\sim 60$ & 62 \\
\hline $\begin{array}{l}\text { Number of days after acceptance to } \\
\text { publication online }\end{array}$ & No online publication & 16 \\
\hline
\end{tabular}




\section{References}

Applegate LM, McFarlan FW, McKenney JL (1996) Corporate information systems management: text and cases. Irwin McGraw-Hill, Boston

Arthur WB (2009) The nature of technology: what it is and how it evolves. Simon \& Schuster, New York

Ba S, Stallaert J, Whinston AB (2001) Research commentary: introducing a third dimension in information systems designthe case for incentive alignment. Inf Syst Res 12(3):225-239

Bapna R, Goes P, Gupta A, Jin Y (2004) User heterogeneity and its impact on electronic auction market design: an empirical exploration. MIS Q 28(1):21-43

Barney J (1991) Firm resources and sustained competitive advantage. J Manag 17(1):99-120

Beck R, Avital M, Rossi M, Thatcher JB (2017) Blockchain technology in business and information systems research. Bus Inf Syst Eng 59(6):381-384

Becker J, König W, Schütte R, Wendt O, Zelewski S (eds) (1999) Wirtschaftsinformatik und Wissenschaftstheorie: Bestandsaufnahme und Perspektiven. Gabler, Wiesbaden

Becker J, Kugeler M, Rosemann M (eds) (2013) Process management: a guide for the design of business processes. Springer, Heidelberg

Becker J, Clever N, Holler J, Neumann M (2018) Business process management in the manufacturing industry: ERP replacement and ISO 9001 recertification supported by the icebricks method. In: vom Brocke J, Mendling J (eds) Business process management cases: digital innovation and business transformation in practice. Springer, Cham, pp 413-429. https://doi.org/10.1007/ 978-3-319-58307-5_22

Beimborn D, Franke J, Gomber P, Wagner H-T, Weitzel T (2006) Die Bedeutung des Alignment von IT und Fachressourcen in Finanzprozessen-Eine Empirische Untersuchung. Wirtschaftsinformatik 48(5):331-339

Bélanger F, Crossler RE (2011) Privacy in the digital age: a review of information privacy research in information systems. MIS Q 35(3): 179-212

Benlian A, Hess T, Buxmann T (2009) Drivers of SaaS-adoption-an empirical study of different. Application types. Bus Inf Syst Eng 1(5):357-369

Bichler M, Frank U, Avison D, Malaurent J, Fettke P, Hovorka D, Krmer J, Schnurr D, Mller B, Suhl L, Thalheim B (2016) Theories in business and information systems engineering. Bus Inf Syst Eng 58(4):291-319

Buhl HU, Lehnert M (2012) Information systems and business \& information systems engineering: status quo and outlook. In: International conference on business information systems, Vilnius. Springer, Heidelberg, pp 1-10

Buhl HU, Fridgen G, König W, Röglinger M, Wagner C (2012a) Where's the competitive advantage in strategic information systems research? Making the case for boundary-spanning research based on the German business and information systems engineering tradition. J Strateg Inf Syst 21(2):172-178. https:// doi.org/10.1016/j.jsis.2012.05.003

Buhl HU, Fridgen G, Müller G, Röglinger M (2012b) On dinosaurs, measurement ideologists, separatists, and happy souls. Bus Inf Syst Eng 4(6):307-315. https://doi.org/10.1007/s12599-0120239-z

Buhl HU, Müller G, Fridgen G, Röglinger M (2012c) Business and information systems engineering: a complementary approach to information systems-what we can learn from the past and may conclude from present reflection on the future. J Assoc Inf Syst 13(4):236-253
Caserta M, Voß S (2014) A hybrid algorithm for the DNA sequencing problem. Discrete Appl Math 163:87-99

Chen P (1976) The entity-relationship model-toward a unified view of data. ACM Trans Database Syst 1(1):9-36

Chiasson M, Davidson E, Winter J (2018) Philosophical foundations for informing the future(S) through IS research. Eur J Inf Syst 27(3):367-379. https://doi.org/10.1080/0960085x.2018.1435232

Clemons EK, Hann IH, Hitt LM (2002) Price dispersion and differentiation in online travel: an empirical investigation. Manag Sci 48(4):534-549

Davenport TH (1993) Process innovation: reengineering work through information technology. Harvard Business Press, Cambridge

del-Río-Ortega A, Resinas M, Durán A, Bernárdez B, Ruiz-Cortés A, Toro M (2017) Visual PPINOT: a graphical notation for process performance indicators. Bus Inf Syst Eng. https://doi.org/10. 1007/s12599-017-0483-3

Dibbern J, Heinzl A (2001) Outsourcing der Informationsverarbeitung im Mittelstand: test eines Multitheoretischen Kausalmodells. Wirtschaftsinformatik 43(4):339-350

Diebold J (1959) Elektronische Computer - Eine Herausforderung für die Unternehmensleitung. elektronische datenverarbeitung 1(1):20-23. Reprint translated as: Electronic computers - the challenge to management. Bus Inf Syst Eng 2009 1(1):81-83

Domschke W, Scholl A (2010) Rundreisen und Touren, 5th edn. Oldenbourg, München

Dumas M, La Rosa M, Mendling J, Reijers HA (2018) Fundamentals of business process management, 2nd edn. Springer, Heidelberg

Durward D, Blohm I, Leimeister JM (2016) Crowd work. Bus Inf Syst Eng 58(4):281-286

Feyerabend PK (1993) Against method, 3rd edn. Verso, London

Fink A, Voß S (2003) Anwendung von Metaheuristiken zur Lösung betrieblicher Planungsprobleme-Potenziale und Grenzen einer softwaretechnischen Unterstützung. Wirtschaftsinformatik 45(4):395-407

Fink A, Kliewer N, Mattfeld D, Mönch L, Rothlauf F, Schryen G, Suhl L, Voß S (2014) Model-based decision support in manufacturing and service networks. Bus Inf Syst Eng $6(1): 17-24$

Frank U (2014) Higher value of research by promoting value for researchers. Commun AIS 34:43

Frank U (2017) Theories in the light of contingency and change: possible future worlds and well-grounded hope as a supplement to truth. In: Proceedings of the 50th Annual Hawaii International Conference on System Sciences. http://hdl.handle.net/10125/ 41853. Accessed 17 Oct 2018

Frank U, Schauer C, Wigand R (2008) Different paths of development of two information systems communities: a comparative study based on peer interviews. Commun Assoc Inf Syst 22(21):391-412

Frank U, Strecker S, Fettke P, vom Brocke J, Becker J, Sinz E (2014) The research field "modeling business information systems". Bus Inf Syst Eng 6(1):39-43

Friedman TL (2005) The world is flat. Penguin, London

Gaitanides M (1983) Prozeßorganisation: Entwicklung, Ansätze und Programme prozeßorientierter Organisationsgestaltung. Vahlen, München

Gassmann O, Frankenberger K, Csik M (2014) Revolutionizing the business model. In: Gassmann O, Schweitzer F (eds) Management of the fuzzy front end of innovation. Springer, Cham, pp 89-97. https://doi.org/10.1007/978-3-319-01056-4_7

Gawer A (2014) Bridging differing perspectives on technological platforms: toward an integrative framework. Res Policy 43(7):1239-1249

Hammer M, Champy J (1993) Reengineering the corporation: a manifesto for business revolution. Harper, New York 
Hasenkamp U, Stahlknecht P (2009) Wirtschaftsinformatik-evolution of the discipline as reflected by its journal. Bus Inf Syst Eng 1(1):14-24. https://doi.org/10.1007/s12599-008-0022-3

Heinrich L (1993) Computerunterstützung kooperativen Arbeitens. Wirtschaftsinformatik 35(2):99-100

Heinrich LJ (1995) Informationsmanagement-Planung, Überwachung und Steuerung der Informationsinfrastruktur, 4th edn. Oldenbourg, München

Heinzl A, Schoder D, Frank U (2008) WI-Journalliste 2008 sowie WI-Liste der Konferenzen, Proceedings und Lecture Notes 2008, Verabschiedete Fassung der WKWI-Sitzung vom 2008-02-27 in München. Wirtschaftsinformatik 50(2):155-163

Hinz O, Spann M, Hann IH (2015) Research note-can't buy me love... or can I? Social capital attainment through conspicuous consumption in virtual environments. Inf Syst Res 26(4):859-870

Hitt LM, Brynjolfsson E (1996) Productivity, business profitability, and consumer surplus: three different measures of information technology value. MIS Q 20(2):121-142

Hui KL, Teo HH, Lee SYT (2007) The value of privacy assurance: an exploratory field experiment. MIS Q 31(1):19-33

Jarke M (2009) Perspectives in the interplay between business and information systems engineering and computer science. Bus Inf Syst Eng 1(1):70-74

Jarke M (2017) Data spaces: combining goal-driven and data-driven approaches in community decision and negotiation support. In: Schoop M, Kilgour DM (eds) Group decision and negotiation17th International Conference GDN 2017, vol 293. Springer LNBIP, pp 3-14

Jarke M, Loucopoulos P, Lyytinen K, Mylopoulos J, Robinson WN (2011) The brave new world of design requirements. Inf Syst 36(7):992-1008

Jouck T, Depaire B (2018) Generating artificial data for empirical analysis of control-flow discovery algorithms: a process tree and $\log$ generator. Bus Inf Syst Eng. https://doi.org/10.1007/s12599018-0541-5

Jung D, Dorner V, Glaser F, Morana S (2018) Robo-advisory: digitalization and automation of financial advisory. Bus Inf Syst Eng 60(1):81-86. https://doi.org/10.1007/s12599-018-0521-9

Kettner KH (1959) Der Integrationseffekt elektronischer Datenverarbeitung. elektronische datenverarbeitung 1(1):14-19. Reprint translated as: The integrative effect of electronic data processing. Bus Inf Syst Eng 2009 1(1):98-103

Kieser A (2012) JOURQUAL: Der Gebrauch, nicht der Missbrauch, ist das Problem. Oder: Warum Wirtschaftsinformatik die beste deutschsprachige betriebswirtschaftliche Zeitschrift ist. Die Betriebswirtschaft 72(1):93-110

Kieser A (2016) Ineffizient, irreführend und teuer: wissenschaftliche Zeitschriften in der Krise. Ansätze zur Reform des Systems wissenschaftlicher Veröffentlichungen. Die Betriebswirtschaft 76(6):467-476

Köbler F, Fähling J, Krcmar H, Leimeister JM (2010) IT governance and types of it decision makers in German hospitals: an empirical study among it decision makers. Bus Inf Syst Eng 2(6):359-370

König W (2002) Industrialisierung des Bankgeschäfts. Wirtschaftsinformatik 44(6):517-518

Krasnova H, Veltri NF, Günther O (2012) Self-disclosure and privacy calculus on social networking sites: the role of culture. Bus Inf Syst Eng 4(3):127-135

Krcmar H (1997) Informationsmanagement. Springer, Heidelberg

Kuhn TS (1964) The structure of scientific revolutions. University of Chicago Press, Chicago

Künne W (2003) Conceptions of truth. Oxford University Press, Oxford
Lacity MC, Willcocks LP (2003) IT sourcing reflections: lessons for customers and suppliers. Wirtschaftsinformatik 45(2):115-125

Lacity MC, Willcocks LP (2016) Robotic process automation at Telefonica O2. MIS Q Exec 15(1):21-35

Lee AS (1999) Researching MIS. In: Currie WL, Galliers B (eds) Rethinking management information systems: an interdisciplinary perspective. Oxford University Press, New York, pp 7-27

Lee I, Lee K (2015) The Internet of Things (IoT): applications, investments, and challenges for enterprises. Bus Horizons 58(4):431-440

Loos P, Mettler T, Winter R, Goeken M, Frank U, Winter A (2013) Methodological pluralism in business and information systems engineering? Bus Inf Syst Eng 5(6):453-460

Maniezzo V, Stützle T, Voß S (eds) (2009) Matheuristics-hybridizing metaheuristics and mathematical programming. Springer, Heidelberg

Mata FJ, Fuerst WL, Barney JB (1995) Information technology and sustained competitive advantage: a resource-based analysis. MIS Q 19(4):487-505

Mendling J, Weber I, van der Aalst W, vom Brocke J et al (2018) Blockchains for business process management—challenges and opportunities. ACM Trans Manag Inf Syst 9(1):1-16

Mertens P, Plattflaut E (1986) Informationstechnik als Strategische Waffe. Inf Manag 1986(2):6-17

Mönch L (2006) Autonome und kooperative Steuerung komplexer Produktionsprozesse mit Multi-Agenten-Systemen. Wirtschaftsinformatik 48(2):107-119

Mooney JG, Gurbaxani V, Kraemer KL (1996) A process oriented framework for assessing the business value of information technology. ACM SIGMIS Database 27(2):68-81

Bichler M (2018a) Editorial statement. Business and Information Systems Engineering. http://www.bise-journal.com/?page_id= 146. Accessed 17 July 2018

Bichler M (2018b) Top 1000 scientists in computer science and electronics. http://www.guide2research.com/scientists/. Accessed 28 Aug 2018

Nievergelt J (1994) Complexity, algorithms, programs, systems: the shifting focus. J Symb Comput 17:297-310

Nordsieck F (1934) Grundlagen der Organisationslehre. Poeschel, Stuttgart

Österle H, Becker J, Frank U, Hess T, Karagiannis D, Krcmar H, Loos P, Mertens P, Oberweis A, Sinz EJ (2011) Memorandum on design-oriented information systems research. Eur J Inf Syst 20(1):7-10. https://doi.org/10.1057/ejis.2010.55

Otto B, Lohmann S, Steinbiß S, Teuscher (eds) (2018) IDS reference architecture model industrial data space, version 2.0. International Data Space Association and Fraunhofer e.V., Berlin

Pentland A (2014) Social physics. Scribe, Brunswick

Penzel H-G (1999) Post Merger Management in Banken-und die Konsequenzen für das IT-Management. Wirtschaftsinformatik 41(2):105-115

Pham MC, Klamma R, Jarke M (2011) Development of computer science disciplines: a social network analysis approach. Soc Netw Anal Min 1(4):321-340

Picot A, Baumann O (2009) The relevance of organization theory to the field of business and information systems engineering. Bus Inf Syst Eng 1(1):62-69. https://doi.org/10.1007/s12599-008$0027-\mathrm{y}$

Porter ME (1980) Competitive strategy: techniques for analyzing industries and competitors. Free Press, New York

Porter ME (2008) The five competitive forces that shape strategy. Harv Bus Rev 86(1):25-40

Porter ME, Millar V (1985) How information gives you competitive advantage. Harv Bus Rev 65(4):149-160 
Potthof I (1998) Empirische Studien zum Wirtschaftlichen Erfolg der Informationsverarbeitung. Wirtschaftsinformatik 40(1):54-65

Puschmann T, Alt R (2016) Sharing economy. Bus Inf Syst Eng 58(1):93-99

Roemer M, Buhl HU (1996) Das World Wide Web als Alternative zur Bankfiliale: gestaltung Innovativer IKS für das Direktbanking. Wirtschaftsinformatik 38(6):565-577

Rogerson S, Miller K, Winter J, Larson D (2017) Information systems ethics challenges and opportunities. J Inf Commun Ethics Soc. https://doi.org/10.1108/jices-07-2017-0041

Roithmayr F, Wendner J (1992) Ergebnisse einer empirischen Studie über den Zusammenhang zwischen Unternehmensstrategie und Informationssystem-Strategie. Wirtschaftsinformatik 34(5):472-480

Rorty R (1999) Philosophy and social hope. Penguin, New York

Ross ME, Boshoff WH (2017) The peer-review system for academic papers is badly in need of repair. The Conversation, 26 Feb 2017. https://theconversation.com/the-peer-review-system-for-aca demic-papers-is-badly-in-need-of-repair-72669. Accessed 17 July 2018

Rowe F (2018) Being critical is good, but better with philosophy! From digital transformation and values to the future of IS research. Eur J Inf Syst 27(3):380-393

Rumelhart DE, Hinton DE, Williams RJ (1986) Learning representations by back-propagating errors. Nature 323:533-536

Scheer AW (1989) Enterprise-wide data modelling. Springer, New York

Schuff HK (1959) Elektronische Datenverarbeitung-Fachberichte über programmgesteuerte Maschinen und ihre Anwendung. In: elektronische datenverarbeitung, vol 1, no 1, pp 3-4

Schuh G, Kampker A, Wesch-Potente C (2011) Condition-based factory planning. Prod Eng 5(1):89-94

Schumann M (1993) Wirtschaftlichkeitsbeurteilung für IV-Systeme. Wirtschaftsinformatik 35(2):167-178

Sein M, Rossi M, Purao S (2007) Exploring the limits of the possible. Scand J Inf Syst 19(2):93-98

Shachaf P (2008) Cultural diversity and information and communication technology impacts on global virtual teams: an exploratory study. Inf Manag 45(2):131-142. https://doi.org/10.1016/j. im.2007.12.003

Smith A (1776) An inquiry into the nature and causes of the wealth of nations. W. Strahan and T. Cadell, London

Soh C, Markus ML (1995) How IT creates business value: a process theory synthesis. In: International conference on information systems, Amsterdam, pp 29-41

Somogyi EK, Galliers RD (1987) Applied information technology: from data processing to strategic information systems. J Inf Technol 2(1):30-41

Spitta T (1998) IV-Controlling in Mittelständischen Industrieunternehmen-Ergebnisse einer empirischen Studie. Wirtschaftsinformatik 40(5):424-433

Sprenger M, Mettler T (2015) Service robots. Bus Inf Syst Eng 57(4):271-274

Straub (2008) Editor's comments: thirty years of service to the IS profession: time for renewal at MISQ? MIS Q 32(1):iii. https:// doi.org/10.2307/25148825

Szyperski N, Schmitz P, Kronen J (1993) Outsourcing: profil und Markt einer Dienstleistung für Unternehmen auf dem Weg zur Strategischen Zentrierung. Wirtschaftsinformatik 35(3):228-240

Uhlemann T, Lehmann C, Steinhilper R (2017) The digital twin: realizing the cyber-physical production system for Industry 4.0. Proc CIRP 61:335-340
Urquhart C, Carte T, Heinzl A (2018) Time for some changes to ICIS? Reflections on our highest-quality conference. Commun Assoc Inf Syst 41(Article 8). http://aisel.aisnet.org/cais/vol41/ iss $1 / 8$. Accessed 17 July 2018

van der Aalst WMP (2016) Process mining-data science in action, 2nd edn. Springer, Heidelberg

van der Aalst W, Bichler M, Heinzl A (2016a) Open research in business and information systems engineering. Bus Inf Syst Eng 58(6):375-379

van der Aalst WMP, La Rosa M, Santoro FM (2016b) Business process management. Bus Inf Syst Eng 58(1):1-6

van der Aalst WMP, Bichler M, Heinzl A (2017) Responsible data science. Bus Inf Syst Eng 59(5):311-313

van der Aalst WMP, Bichler M, Heinzl A (2018) Robotic process automation. Bus Inf Syst Eng 60(4):269-272. https://doi.org/10. 1007/s12599-018-0542-4

Voigt F (1832) Der Handlungsreisende-wie er sein soll und was er $\mathrm{zu}$ tun hat, um Aufträge zu erhalten und eines glücklichen Erfolgs in seinen Geschäften gewiß zu sein-von einem alten Commis-Voyageur (The travelling salesman-how he must be and what he should do in order to get commissions and be sure of the happy success in his business - by an old commis-voyager)

vom Brocke J, Mendling J (2018) Business process management cases. Digital innovation and business transformation in practice. Springer, Cham

vom Brocke J, Rosemann M (2010) Handbook on business process management. Springer, Heidelberg

Vosoughi S, Roy D, Aral S (2018) The spread of true and false news online. Science 359(6380):1146-1151

Voß S (2014) Interview with Daniel Dolk and Christer Carlsson on "Decision Analytics". Bus Inf Syst Eng 56(3):181-184

Weber R (1997) Ontological foundations of information systems. Coopers \& Lybrand, Melbourne

Weber I, Xu X, Riveret R, Governatori G, Ponomarev A, Mendling J (2016) Untrusted business process monitoring and execution using blockchain. In: International conference on business process management. Springer, Cham, pp 329-347

Weinhardt C, Anandasivam A, Blau B, Borissov N, Meinl T (2009) Cloud computing - a classification, business models, and research directions. Bus Inf Syst Eng 1(5):391-399

Willcocks L, Lacity M (2016) Service automation: robots and the future of work. SB Publishing, Ashford

Winter R (2003) Modelle, Techniken und Werkzeuge im Business Engineering. In: Business engineering. Springer, Heidelberg, pp 87-118

Winter R (2010) Interview with Jay F. Nunamaker, Jr. on "Toward a broader vision of IS research". Bus Inf Syst Eng 2(5):321-329

Zachman JA (1987) A framework for information systems architecture. IBM Syst J 26(3):276-292

Zdravkovic J, Stirna J, Kirikova M, Karagiannis D, Winter R (2015) Advanced enterprise modeling. Bus Inf Syst Eng 57(1):1-2. https://doi.org/10.1007/s12599-014-0367-8

Zuboff S (1988) In the age of the smart machine: the future of work and power. Basic Books, New York

zur Muehlen M (2004) Workflow-based process controlling: foundation, design, and application of workflow-driven process information systems. Logos, Berlin 